\title{
The Effect of TLR9 Agonist CpG Oligodeoxynucleotides on the Intestinal Immune Response of Cobia (Rachycentron canadum)
}

\author{
Omkar Byadgi, ${ }^{1}$ Dinda Puteri, ${ }^{1,2}$ Jai-Wei Lee, ${ }^{1}$ Tsung-Chou Chang, ${ }^{3}$ Yan-Horn Lee, \\ Chun-Yen Chu, ${ }^{5}$ and Ta-Chih Cheng ${ }^{1}$ \\ ${ }^{1}$ Department of Tropical Agriculture and International Cooperation, National Pingtung University of Science and Technology, \\ Pingtung 91201, Taiwan \\ ${ }^{2}$ Department of Fisheries and Marine Science, University of Brawijaya, Malang 65145, Indonesia \\ ${ }^{3}$ Anatomy \& Pathology Laboratory, Department of Veterinary Medicine, National Pingtung University of Science and Technology, \\ Pingtung 91201, Taiwan \\ ${ }^{4}$ Tungkang Biotechnology Research Center, Fisheries Research Institute, Council of Agriculture, Pingtung 91201, Taiwan \\ ${ }^{5}$ Graduate Institute of Animal Vaccine Technology, National Pingtung University of Science and Technology, Pingtung 91201, Taiwan
}

Correspondence should be addressed to Ta-Chih Cheng; cheng.tachih@gmail.com

Received 27 December 2013; Revised 11 April 2014; Accepted 22 April 2014; Published 2 June 2014

Academic Editor: Yong-Suk Jang

Copyright (C) 2014 Omkar Byadgi et al. This is an open access article distributed under the Creative Commons Attribution License, which permits unrestricted use, distribution, and reproduction in any medium, provided the original work is properly cited.

\begin{abstract}
Cytosine-guanine oligodeoxynucleotide (CpG ODN) motifs of bacterial DNA are recognized through toll-like receptor 9 (TLR9) and are potent activators of innate immunity. However, the interaction between TLR9 and CpG ODN in aquatic species has not been well characterized. Hence, cobia TLR9 isoform B (RCTLR9B) was cloned and its expression and induction in intestine were investigated. RCTLR9B cDNA consists of 3113bp encoding 1009 amino acids containing three regions, leucine rich repeats, transmembrane domain, and toll/interleukin-1 receptor (TIR) domain. Intraperitoneal injection of CpG ODN 2395 upregulated RCTLR9 A and B and MyD88 and also induced the expressions of Mx, chemokine CC, and interleukin IL-1 $\beta$. Cobia intraperitoneally injected with CpG ODN 1668 and 2395 had increased survival rates after challenge with Photobacterium damselae subsp. piscicida. In addition, formulation of CpG ODN with formalin-killed bacteria (FKB) and aluminum hydroxide gel significantly increased expressions of RCTLR9 A (50 folds) and B (30 folds) isoforms at $10 \mathrm{dpi}$ (CpG ODN 1668) and MyD88 (21 folds) at $6 \mathrm{dpv}$ (CpG ODN 2395). Subsequently, IL-1 $\beta$ increased at $6 \mathrm{dpv}$ in 1668 group. No histopathological damage and inflammatory responses were observed in the injected cobia. Altogether, these results facilitate CpG ODNs as an adjuvant to increase bacterial disease resistance and efficacy of vaccines in cobia.
\end{abstract}

\section{Introduction}

Teleost innate immunity plays an important role in the initial protection against invading pathogens [1]. The gastrointestinal (GI) tract is generally recognized as an organ crucial not only to the digestion/absorption of nutrients, but also to the immunity [2]. The GI tract serves as an important barrier and protects the fish from feed-borne pathogens [3-5]. The posterior segment of fish intestine is immunologically active and is armored with various immune cell types, including $\mathrm{B}$ cells, macrophages, granulocytes, and $\mathrm{T}$ cells, that play vital roles in local immune responses during the course of immunization and inflammation [6-8]. In addition, the fish intestinal epithelial cells are constantly exposed to pathogens and are involved in the innate immunity of GI tract. These cells recognize pathogen-associated molecular patterns (PAMPs) through the toll-like receptors (TLRs) and induce immune responses in the intestinal lumen [9].

TLRs are transmembrane proteins recognizing conserved pathogenic structures and activating immune effector molecules [10] to form a linkage between innate and adaptive immunity [11]. The main immune functions of TLRs are (1) inducing the expressions of pro/anti-inflammatory, cyto- and chemokine that link to the adaptive immune 
system; (2) initiating antimicrobial effects or pathways; and (3) maintaining commensal and mucosal homeostasis [12]. The role that toll-like receptor 9 (TLR9) plays in the innate immune responses to bacterial and synthetic DNA containing unmethylated $\mathrm{CpG}$ motifs has been well characterized [13]. The human TLR9 gene can splice into different isoforms during transcription generating 5 TLR9 isoforms (TLR9A, $\mathrm{B}, \mathrm{C}, \mathrm{D}$, and E). These TLR9 isoforms are differentially expressed in various immune organs and cells, such as spleen, peripheral blood mononuclear cells (PBMC), and lymph nodes, which may attribute to differential profiles of proinflammatory cytokines and cytotoxic T-lymphocyte differentiation [14-16]. In teleost, only sea bream and croaker TLR9 B isoforms have been identified, but the functions of TLR9 B isoforms remain unclear $[10,17]$.

Cytosine phosphate-guanine (CpG) oligodeoxynucleotides (ODNs) are DNA fragments with a high frequency of $\mathrm{CpG}$ motifs simulating the immunostimulatory activity of bacterial DNA $[18,19]$. CpG ODNs, unlike most conventional adjuvants, are able to stimulate both humoral and cell-mediated immune responses in immunized animals [20]. The interaction of TLR9 with CpG motifs initiates a cascade of events resulting in the secretion of $\mathrm{T}$ helper (Th) 1-type cytokines and chemokines. Productions of the chemokine and interferon-gamma-inducible protein-10 (IP10) are early indicators of Thl type immune responses [21, 22]. In mammals, intraperitoneal administration of $\mathrm{CpG}$ ODNs is effective in stimulating the expressions of intestinal TLR9 and chemokines due to the lower interleukin (IL)10 level in human neonates and pig intestine [23, 24]. In teleost, administration of $\mathrm{CpG}$ ODNs has been found to increase TLR9 expression in Atlantic salmon [25], sea bream [26], and turbot [27]. However, to our best knowledge, the immune responses involved in the gut immunity in response to intraperitoneal stimulation of $\mathrm{CpG}$ ODNs in cobia have not been investigated.

The cobia industry has been suffering from various infectious diseases associated with Photobacterium damselae (P. damselae) subsp. piscicida [28-31] that has a high binding and invading capacity to the epithelial cells of fish intestine $[32,33]$. Hence, the immunostimulatory effects of $\mathrm{CpG}$ ODNs might be able to enhance the intestinal immunity of cobia and increase the resistance to infections caused by $P$. damselae subsp. piscicida. The objectives of this study are to (1) clone RCTLR9B; (2) analyze the expressions of RCTLR9A RCTLR9B, MyD88, Mx, IgM, chemokine CC, and IL-1 $\beta$ in response to the stimulation of CpG ODNs; (3) evaluate the protection efficiency of intraperitoneal administration of CpG ODNs against $P$. damselae subsp. piscicida infections; and (4) assess the CpG adjuvanticity by intraperitoneal injection of $\mathrm{CpG}$ ODNs formulated with formalin-killed bacteria (FKB) and aluminum hydroxide gel (alum).

\section{Materials and Methods}

\subsection{Cloning of Cobia TLR9 Isoform B}

2.1.1. Partial Cloning of Cobia TLR9 Isoform B. Partial sequence of cobia TLR9B was obtained using the primers
(TLR9F1 and TLR9R1) which were designed based on TLR9 sequences of other fish species (Acanthopagrus berda number EU256332, Dentex tumifrons number EU256335, Larimichthys crocea A number EU655704, Larimichthys crocea B number EU655705, Sparus aurata A number AY751797, and Sparus aurata B number AY751796) using Vector-NTI (Invitrogen, Carlsbad, CA, USA) [34]. PCR was carried out using cobia cDNA from the liver as a template under the following condition: one cycle at $95^{\circ} \mathrm{C}$ for $2 \mathrm{~min}$ followed by 35 cycles of $95^{\circ} \mathrm{C}$ for $30 \mathrm{~s}, 54^{\circ} \mathrm{C}$ for $30 \mathrm{~s}$, and $72^{\circ} \mathrm{C}$ for $1 \mathrm{~min}$; and a final extension at $72^{\circ} \mathrm{C}$ for $5 \mathrm{~min}$. PCR products were sequenced and used for designing real-time PCR primers.

2.1.2. Rapid Amplification of cDNA Ends (RACE). To obtain the full-length cDNA sequence of RCTLR9 isoform B (RCTLR9B), $5^{\prime}$ and $3^{\prime}$ RACE were implemented using the SMARTer RACE cDNA amplification kit (Clontech, USA). The RCTLR9 gene primers, TLR9B-RacF1 and TLR9BRacR1, were designed from the partial RCTLR9B cDNA sequence (JX073035.1). Touchdown-PCR was carried out for $3^{\prime}$ and $5^{\prime}$ RACE using TLR9B-Rac F1/UPM and TLR9BRacR1/UPM primer sets (Table 1), under the following conditions: one cycle of initial denaturation at $94^{\circ} \mathrm{C}$ for $2 \mathrm{~min}$ followed by 5 cycles of $94^{\circ} \mathrm{C} / 30 \mathrm{~s}$, and $72^{\circ} \mathrm{C} / 3 \mathrm{~min}$; next 5 cycles $94^{\circ} \mathrm{C} / 30 \mathrm{~s}, 70^{\circ} \mathrm{C} / 30 \mathrm{~s}$, and $72^{\circ} \mathrm{C} / 3 \mathrm{~min}$; next 25 cycles $94^{\circ} \mathrm{C} / 30 \mathrm{~s}, 68^{\circ} \mathrm{C} / 30 \mathrm{~s}$, and $72^{\circ} \mathrm{C} / 3 \mathrm{~min}$; and one cycle at $72^{\circ} \mathrm{C} / 5 \mathrm{~min}$. Nested PCR for $5^{\prime}$ and $3^{\prime}$ RACE was performed using TLR9B-NGSP1/NUP for $5^{\prime}$ and TLR9BNGSP2/NUP for $3^{\prime}$ nested primer sets (Table 1). For nested PCR, $1 \mu \mathrm{L}$ of primary RACE-PCR product was used as a template with the following conditions: initial one cycle of $94^{\circ} \mathrm{C} / 2 \mathrm{~min}$ and then 30 cycles of $94^{\circ} \mathrm{C} / 30 \mathrm{~s}, 68^{\circ} \mathrm{C} / 30 \mathrm{~s}$, and $72^{\circ} \mathrm{C} / 3 \mathrm{~min}$ followed by one cycle of $72^{\circ} \mathrm{C} / 5 \mathrm{~min}$. The PCR products were sequenced and analyzed using Vector-NTI program and BLASTx was performed using NCBI website (http://www.ncbi.nlm.nih.gov/blast/) on the GenBank database.

2.1.3. Analysis of TLR9 cDNA Sequences. The full-length cDNAs of RCTLR9B were assembled using vector NTI program. The deduced amino acid sequence, molecular weight $(\mathrm{kDa}), \mathrm{pI}$, and protein analysis were conducted by the ExPASy proteomic tool (http://www.expasy.org/tools/). The protein domains were predicted using SMART software (http://smart.embl-heidelberg.de/). Homologous sequences were searched using BLAST program available at the NCBI website with default settings on the GenBank database. The multiple sequence alignment was created using the CLUSTALW (http://www.ebi.ac.uk/clustalw2/).

2.2. $C p G$ ODNs. CpG ODNs were purchased from Bioneer (Korea). The ODNs were phosphorothioate modified 
TABle 1: Primer name, sequence, product size, and target gene details used in this study.

(a) Primers used for cloning of TLR9 isoform B

\begin{tabular}{llc}
\hline Primer name & Primer sequence $\left(5^{\prime}-3^{\prime}\right)$ & Application \\
\hline TLR9F1 $^{\text {a }}$ & ATCTCAGCCACAATCAGATC & Partial cloning \\
TLR9R2 $^{\mathrm{a}}$ & AGTTTGGGAAACATCTCATC & \\
\hline TLR9B1 RacF $^{\mathrm{b}}$ & CTGTGAATACCCTGAGTCTCAACAGGG & \\
TLR9B RacR $^{\mathrm{b}}$ & GTGATGCTGTGAATCAGTACCAGCC & \\
$\begin{array}{l}\text { Universal primer } \\
\text { mix (UPM) }\end{array}$ & Long $0.2 \mu$ M CTAATACGACTCACTATAGGGCAAGCAGTGGTATCAACGCAGAGT & \\
$\begin{array}{l}\text { Nested universal } \\
\text { primer mix (NUP) }\end{array}$ & AAGCAGTGGTATATCAACGCAGAGT & \\
TLR9B1-NGSP1 & GCCTTTATGTCCTGCCCAAAGCACC & RACE \\
TLR9B-NGSP2 & CTTCCTCGTCTGTTCCATCTTGGCTGT & \\
\hline
\end{tabular}

(b) Primers used for gene expression studies

\begin{tabular}{|c|c|c|c|c|c|}
\hline Primer name & Primer sequence $\left(5^{\prime}-3^{\prime}\right)$ & Product size (bp) & Target gene & Gene bank accession number & Application \\
\hline $\bar{B} 3-5^{\mathrm{c}}$ & ACAGACTGTTCСТCСТСССС & \multirow{2}{*}{532} & \multirow{2}{*}{$3^{\prime} \mathrm{UTR}$} & \multirow{2}{*}{ HM754627 } & \multirow{4}{*}{ cDNA quality } \\
\hline B3- $2^{\mathrm{c}}$ & GAAACCTCCAACAGCGGG & & & & \\
\hline RAF & AAGGACCTGTACGCCAACA & \multirow{2}{*}{330} & \multirow{2}{*}{$\beta$-Actin-3 } & \multirow{2}{*}{ HM754627 } & \\
\hline RB1 & TGGCGTCTCGCATCGTTT & & & & \\
\hline $\begin{array}{l}\text { TLR9A-RC F } \\
\end{array}$ & TCTGTTCCATCTTGGCTGTG & \multirow{2}{*}{160} & \multirow{2}{*}{ TLR9A } & \multirow{2}{*}{ KC180322 } & \\
\hline TLR9A-RC R & CTGGTTTCTGGTGTCAAACA & & & & \\
\hline TLR9B-RC F & GCCTTCCTCGTCTGTTCCAT & \multirow[t]{2}{*}{178} & \multirow{2}{*}{ TLR9B } & \multirow{2}{*}{ JX073035.1 } & \\
\hline TLR9B-RC R & ACAGCCTGGTTTCTGGTGTC & & & & \\
\hline MyD88-F1Q & GAGGTGTAAGAGGATGGTGGT & \multirow{2}{*}{183} & \multirow{2}{*}{ MyD88 } & \multirow{2}{*}{ KF018033.1* } & \\
\hline MyD88-R2Q & GGTGGGGAATGGCTTTGTCAT & & & & \\
\hline RCIL-1 $\beta \mathrm{F} 1$ & CAGGCAGAACAACCACTGAC & \multirow{2}{*}{170} & \multirow{2}{*}{ IL-1 $\beta$} & \multirow{2}{*}{ AY641829 } & \\
\hline RCIL-1 $\beta$ R2 & TTCCAAGTCCAGTCCTTTGG & & & & $a$ RT_PCR \\
\hline RCMxF1 & TGGACATAGCAACCACAGAG & \multirow{2}{*}{157} & \multirow{2}{*}{$\mathrm{Mx}$} & \multirow{2}{*}{ AY834185 } & \\
\hline RCMxR2 & TTCTTCAGGTGGATGACCTC & & & & \\
\hline RCIgM-F1 & AGACAGCCTGCAGGGAAAAG & \multirow{2}{*}{182} & \multirow{2}{*}{ IgM } & \multirow{2}{*}{ JX025102 } & \\
\hline RCIgM-R2 & TGTTCСТTTCССССAGTAGT & & & & \\
\hline $\mathrm{CCleF}$ & ATTACAATAAGAACCCTGTGC & \multirow{2}{*}{185} & \multirow{2}{*}{$\mathrm{CC}$} & \multirow{2}{*}{ JF975593 } & \\
\hline CCleR & TCTTTCCTGGGATGGATTTG & & & & \\
\hline$\beta$-Actin RC-F & ACAGACTGTTCСТCСТСССС & \multirow{2}{*}{160} & \multirow{2}{*}{$\beta$-Actin-3 } & \multirow{2}{*}{ HM754627 } & \\
\hline$\beta$-Actin RC-R & AAAATCCTGAGTCAAGCGCC & & & & \\
\hline
\end{tabular}

${ }^{\mathrm{a}}$ Partial sequence primers.

${ }^{\mathrm{b}}$ Touchdown primers for $5^{\prime}$ and $3^{\prime}$ designed from TLR9 isoform B partial sequence.

${ }^{c}$ Primers designed from $3^{\prime}$ UTR of cobia $\beta$-actin-3.

${ }^{*}$ Partial sequence cloned in this study.

throughout the sequence. Sequences of $\mathrm{CPG}$ ODNs are as follows:

B-Class CpG $1668 \mathrm{~T} * \mathbf{C} * \mathbf{G} * \mathrm{~T} * \mathbf{C} * \mathbf{G} * \mathrm{~T} * \mathrm{~T} * \mathrm{~T} * \mathrm{~T} * \mathrm{G}$ $* \mathrm{~T} * \mathbf{C} * \mathbf{G} * \mathrm{~T} * \mathrm{~T} * \mathrm{~T} * \mathrm{~T} * \mathrm{G} * \mathrm{C} * \mathrm{~T} * \mathrm{G}$,

C-Class CpG $2395 \mathrm{~T} * \mathbf{C} * \mathbf{G} * \mathrm{~T} * \mathbf{C} * \mathbf{G} * \mathrm{~T} * \mathrm{~T} * \mathrm{~T} * \mathrm{~T} * \mathbf{C}$ $* \mathbf{G} * \mathrm{G} * \mathbf{C} * \mathbf{G} * \mathbf{C} * \mathbf{G} * \mathbf{C} * \mathbf{G} * \mathbf{C} * \mathbf{C} * \mathbf{G}$ and 2137 (control $\mathrm{CpG}$ with phosphorothioate modified inverted),

$\mathrm{T} * \mathbf{G} * \mathbf{C} * \mathrm{~T} * \mathbf{G} * \mathbf{C} * \mathrm{~T} * \mathrm{~T} * \mathrm{~T} * \mathrm{~T} * \mathrm{G} * \mathrm{~T} * \mathbf{G} * \mathbf{C} * \mathrm{~T} * \mathrm{~T} * \mathrm{~T} *$ $\mathrm{T} * \mathrm{G} * \mathrm{~T} * \mathrm{G} * \mathbf{C} * \mathrm{~T} * \mathrm{~T}$ (phosphorothioate modifications are marked with * and CG and GCs are in bold).
The CpG ODNs were suspended in phosphate buffer saline (PBS, $\mathrm{pH} 7.2$ ) and stored at $-20^{\circ} \mathrm{C}$ until used.

2.3. Experimental Design and Fish Sampling. Cobia fish (approximately $20 \mathrm{~g}$ body weight) were procured from a local farm and they were maintained in recirculatory aerated tanks for acclimatization up to one week. During acclimatization, they were fed with a commercial diet and proper water quality (water level $200 \mathrm{~L}$, temperature $28^{\circ} \mathrm{C}$, and salinity $30 \mathrm{ppt}$ ) was maintained. Fish were randomly divided into four groups and each tank was stocked with ten fish $(25 \mathrm{~g})$. Fish were intraperitoneally (i.p.) injected with $0.5 \mathrm{~mL}$ PBS for 
the control group and $0.5 \mathrm{~mL}$ PBS containing $10 \mu \mathrm{g}$ unmethylated CpG ODN 1668, 2395, and 2137, respectively. At each time interval (1, 3, 6, and 10 days after stimulation), two fish were sampled and the posterior part of the intestine was hygienically dissected and immersed in PBS ( $\mathrm{pH}$ 7.2). After the mucus and digested feed inside the intestine were completely removed, the samples were immediately immersed in TRIzol reagent (Invitrogen, USA). Total RNA isolation of the intestine was carried out according to manufacturer's instruction with minor modifications. The RNA pellet was dissolved in Rnase free water (Qiagen) and preserved in $-80^{\circ} \mathrm{C}$ until used.

2.4. Protection Efficiency of Intraperitoneal Administration of CpG ODNs against Bacterial Challenge in Cobia. Cobia fish (20-25 g) were divided into five groups ( $n=10$ each) and acclimatized for three days. During acclimatization, fish were fed with a commercial feed daily. After three days, cobia were injected intraperitoneally (i.p) with $0.5 \mathrm{~mL}$ of PBS and $0.5 \mathrm{~mL}$ PBS containing $10 \mu \mathrm{g}$ CpG ODNs 1668, 2395, and 2137. After $48 \mathrm{~h}$, cobia were challenged intraperitoneally (i.p) with live $P$. damselae subsp. piscicida bacteria $\left(\mathrm{LD}_{50}-3.25 \times\right.$ $\left.10^{6} \mathrm{CFU} / \mathrm{mL}\right)$. Thereafter, the water quality was properly maintained by vigorous aeration and by monitoring constant water temperature and salinity $\left(28^{\circ} \mathrm{C}\right.$ and $\left.30 \mathrm{ppt}\right)$. The behavior and mortality after challenge were recorded daily in individual group.

\subsection{The Adjuvanticity of CPG ODNs}

2.5.1. Preparation of Bacterial Antigens. Bacteria were prepared from the frozen stock using the following conditions: P. damselae subsp. piscicida (BCRC 9714) was cultured in $5 \mathrm{~mL}$ brain heart infusion (BHI) broth containing $2 \% \mathrm{NaCl}$ at $28^{\circ} \mathrm{C}$ /overnight and then $1 \mathrm{~mL}$ broth of the stock was transferred to $100 \mathrm{~mL}$ broth and grown until the O.D reaches $1.0(600 \mathrm{~nm})$. The bacteria were harvested by centrifugation $(6000 \times \mathrm{g})$ at $4^{\circ} \mathrm{C}$ for $5 \mathrm{~min}$. The pellet was washed twice in PBS (pH 7.2) and the bacterial suspension was inactivated by adding formalin to a final concentration of $3 \%$ and incubated overnight at $4^{\circ} \mathrm{C}$. The inactivated bacterial solution was centrifuged at $6000 \times \mathrm{g}$ for $10 \mathrm{~min}$ and thoroughly washed 3 times to remove formalin residues. The inactivation of FKB was confirmed by plating $100 \mu \mathrm{L}$ of solution on $\mathrm{BHI}+2 \%$ $\mathrm{NaCl}$ plates and incubated at $28^{\circ} \mathrm{C}$ overnight.

2.5.2. Formulation of CPG ODNs with FKB and Alum. Each dose $(100 \mu \mathrm{L})$ of vaccine contained $10 \mu \mathrm{g}$ of CpG ODNs (1668, 2395 , or the control 2137) in $10 \mu \mathrm{L}$ PBS formulated with $45 \mu \mathrm{L}$ of $2 \%$ alum (Alhydrogel, Invivogen) and $45 \mu \mathrm{L}$ of FKB. Formulations were mixed at room temperature on a shaker at approximately $30 \mathrm{rpm}$ for $30 \mathrm{~min}$ and stored at $4^{\circ} \mathrm{C}$ until used.

2.5.3. Immunization and Sampling. All cobia were procured from a local fish farm in Pingtung, Taiwan, and were acclimatized as previously described. After acclimatization, twenty fish per tank were stocked into four different groups. The first group was immunized intraperitoneally (i.p.) with $100 \mu \mathrm{L}$
PBS. The second group was immunized with $100 \mu \mathrm{L} /$ fish vaccine containing $10 \mu \mathrm{g} / 10 \mu \mathrm{L}$ of $1668 \mathrm{CpG}$ ODNs plus $45 \mu \mathrm{L}$ FKB. The third (FKB + alum + CpG ODN 2395) and fourth groups $(\mathrm{FKB}+$ alum +2137$)$ were immunized with $45 \mu \mathrm{L}$ of $2 \%$ alum designated as FKB + alum + CpG ODN 1668. All formulations were injected in a total volume of $100 \mu \mathrm{L} /$ fish. After injection, the behavior of fish was observed daily and the optimal conditions were maintained. For gene expression studies, the posterior intestine was sampled for total RNA isolation at 1,3,6, and 10 days after injection (dpi) as described in Section 2.3.

2.5.4. Histopathology. Two fish from each group were sacrificed at 3, 6, and $10 \mathrm{dpi}$, respectively, for histopathological examination. Tissue samples from the posterior part of the intestine were fixed in $10 \%$ neutral buffered formalin for standard procedures of light microscopy. Samples were processed, paraffin-embedded (Tissue-Tek TEC), and cut into 4-5 $\mu \mathrm{m}$ sections using standard microtome (Leica RM2235) before being stained with hematoxylin and eosin (TissueTek DRS). Stained slides were examined (Olympus) for signs of inflammation, dilation of lamina propria, and necrosis of epithelial cells using a double blind design. Slides were recoded to avoid observation bias before they were sent to the pathologist for further examination.

The sign of inflammation was scored from 0 to $3(0$ = normal, $1=$ mild, $2=$ moderate, and $3=$ severe) [35]. Dilation of lamina propria, necrosis of epithelial cells, atrophy, deposits, serosa necrosis, submucosal necrosis, hypertrophy, and hyperplasia were also evaluated based on the histopathological changes as (-) no histopathology, $(+)$ mild histopathology, $(++)$ moderate histopathology, and $(+++)$ severe histopathology.

2.6. cDNA Synthesis and Quantitative Gene Expression. The quality of total RNA was analyzed by a spectrophotometer using 260/280 nm UV. First strand cDNA was synthesized by reverse transcriptase on $2 \mu \mathrm{g}$ of total RNA using MULV reverse transcriptase enzyme (Lucigen, USA) with an oligo-dT primer. All the cDNA samples were stored at $-20^{\circ} \mathrm{C}$ until used. The genomic contamination and quality of cDNA synthesis were determined by using PCRamplification by designing primers on intron-exon flanking region and $3^{\prime} \mathrm{UTR}$ region of cobia $\beta$-actin 3 (HM754627). The expression levels of TLR9 A and B (KC180322 and JX073035), MyD88 (KF018033), IL-1 $\beta$ (AY641829), Mx (AY834185), IgM (JX025102), and CC-chemokine (JF975593) were analyzed by gene specific primers (Table 1). Real-time PCR was carried out in an ABI 7500 real-time detection system (Applied Biosystems, USA). The amplification was performed in a total volume of $10 \mu \mathrm{L}$, containing $5 \mu \mathrm{L}$ of SYBR green I realtime PCR master Mix (Kapa Biosystems), $1 \mu \mathrm{L}$ of cDNA, $0.2 \mu \mathrm{L}$ of each primer, and $3.6 \mu \mathrm{L}$ of DEPC water. The realtime PCR program was $95^{\circ} \mathrm{C}$ for $1 \mathrm{~min}$ followed by 40 cycles of $95^{\circ} \mathrm{C}$ for $15 \mathrm{~s}, 60^{\circ} \mathrm{C}$ for $60 \mathrm{~s}$. Dissociation and melting curve of amplification products was performed at the end of each PCR to confirm that only one PCR product was amplified and detected. After amplification, data acquisition 
Cobia TLR9 isoform $\mathrm{B}$ Cobia TLR9 isoform A Zebrafish TLR9 Mouse TLR9

Cobia TLR9 isoform $\mathrm{B}$ Cobia TLR9 isoform A Zebrafish TLR9 Mouse TLR9

Cobia TLR9 isoform B Cobia TLR9 isoform A Zebrafish TLR9 Mouse TLR9

Cobia TLR9 isoform $\mathrm{B}$ Cobia TLR9 isoform A Zebrafish TLR9

Mouse TLR9

Cobia TLR9 isoform B Cobia TLR9 isoform A Zebrafish TLR9

Mouse TLR9

Cobia TLR9 isoform $\mathrm{B}$ Cobia TLr9 isoform A Zebrafish TLR9 Mouse TLR9

Cobia TLR9 isoform $\mathrm{B}$ Cobia TLr9 isoform A Zebrafish TLR9

Mouse TLR9

Cobia TLR9 isoform B Cobia TLr9 isoform A Zebrafish TLR9 Mouse TLR9

Cobia TLR9 isoform B Cobia TLr9 isoform A Zebrafish TLR9

Mouse TLR9

Cobia TLR9 isoform B Cobia TLr9 isoform A Zebrafish TLR9

Mouse TLR9

Cobia TLR9 isoform $B$ Cobia TLr9 isoform A Zebrafish TLR9 Mouse TLR9

Cobia TLR9 isoform B Cobia TLr9 isoform A Zebrafish TLR9 Mouse TLR9
Signal peptide

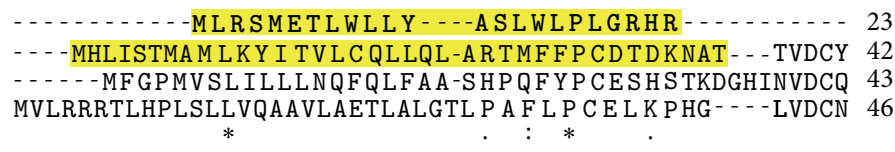

FGIALS - - - - LNLSRTKIQQVGWRDFAGVPNLQTLKIMG 58 DRPLKYVPLIESDTVVS - - - - LNLSRTKIQQVGWRDFAGVPNLQTLKIMG 88 HRRLSKVPRFTSPSVIS - - - - LNLNNNH I HR IKGDAFSGLPNLKYLSLMW 89 WLFLKSVPRFSAAASCSNITRL SL ISNR I HHLHNSDFVHLSNLRQLNLKW 96 * $\quad * . * \quad .: *::: \quad * \quad: . * *: * .:$

LRR 1

NCQPGQLS - - - - CKMK INYY AFKSLLKLKFLHLSGNSLTT I PWLPESL 102 NCQPGQLS - - - - - CKMK INYYAFK SLLKLKFLHLSGNSLTTIPWLPESL 132 NCISDRLKEARWPLCSVN IDPDAFVGLKNLTSLQLAGNSLKMIPPLPKQL 139 NCPPTGLSPLHFS - CHMT IEPRTFLAMRTLEELNLSYNGITTVPRLPSSL 145

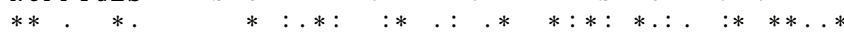

RVLDLQHNHIFHITH - -FYKTPYLKELFLSKNCFYTNPCNQSFYINESVF 150 RVLDLQHNHIFHITH - -FYKTPYLKELFLSKNCFYTNPCNQSFYINESVF 180 EVLGLEFNNIFNIVK - - PLGTPQLKQLLLSKNCFYANPCHQPYFINSSVF 187 VNLSLSHTNILVLDANSLAGLYSLRVLFMDGNCYYKNPCTGAVKVTPGAL 195

LRRTYP

LRR2

WGLHKLKTLMLGYNNLTSVPKRLPSSLENLDLKENAITEVLEGAFTNLPL 200 WGLHKLKTLMLGYNNLTSVPKRLPSSLENLDLKENAITEVLEGAFTNLPL 230 QDLPELLNLTLSYNNLTAIPSYLPGSLESLDLRENTIDHINKESFANLRN 237 LGLSNLTHLSL KYNNLTKVPRQLPPSLEYLLVSYNLIVKLGPEDLANLTS 245

LRR3

LKTLNLEWNCQRCDHAARPCFPCPQNFPLKLYPNSFYAKNSSITYLSLRG 250 LKTLNLEWNCQRCDHAARPCFPCPQNFPLKLYPNSFYAKNSSITYLSLRG 280 LRHLNLGWNCQRCDHA SDP CF PCPNNQS LD LHQDAF LDQRD SL VSLHLQG 287 LRVLDVGGNCRRCDHAPNPC IECW QK - SLHLHPETFH - HL SHLEGLVLKD 293 $*: *:: * *: * * * * *, * *: *$ : : $, *, *: \quad:: * \quad: \quad .:$ : $* *$ :

LRR3

LRR4

NSLKTFPEGLFRPLKNLKRLDLSDNFLAYAIRNGTFFSELKGLTWISLIY 300 NSLKTFPEGLFRPLKNLKRLDLSDNFLAYAIRNGTFFSELKGLTW ISLIY 330 NSLRTLPRHLFINLHKLQELDLSSNFLAFTIQNGTFYEELQNVVILNLLY 337

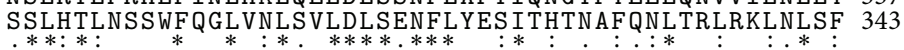

LRR5

NYEPLRTFPKLILSPYIAN ISGLEHLLLSGNFFHQLSNQSFSVLSKLKNL 350 NYEPLRTFPKL I LSPY I AN I SGLEHLLLSGNFFHQLSNQSF SVLSKLKNL 380 NYEPLKTFPELNLSPY IEKMASLRELYLSGFFFKKLSNRS IAPLVKLPRL 387 NYRKKVSTFARLHLAS SFKN L V SLQELNMNG IFFRLLNKYTLRWLADLPKL 393

LRR6

LRR7

KRLELRMNF INTCNLTKLKQLPSLINIDLSQNMLSFLPCCSNSKQKSCDD 400 KRLELRMNF INTCNLTKLKQLPSL INIDLSQNMLSFLPCCSNSKQKSCDD 430 EVLDLRMNF ICD IS IDGLSQLRTLRRVDLSQNMLAFSSCFSTCTS - - - EA 434 HTLHLQMNF INQAQLSIFGTFRALRFVDLSDNRISGPSTLSEATP - - - - 438

. *.*:****: : $\quad: \quad: \quad: * \quad: * * *: * \quad:: \quad$ : $*$.

QNLYTHNLHDQPHIVRDREVTSVNEINESNQDNVMELVEGNASHFPSILD 450 QNLYTHNLHDQPHIVRDREVTSVNEINESNQDNVMELVEGNASHFPSILD 480 EHQIPERYGNEQFNLQMQELPILNAETQGSK - - - - - PDYCSFYFSMWH 477 - - - - - EEADDAEQEELLSADPHPAPLS - - - - - - TPASKN 466

$$
\text { .*: }
$$

FRNHFCQHKLTYDLSQND ILSLDKHVFSGMENAVCLDLSYNYMSQALRRG 500 FRNHFCQHKLTYDLSQNDILSLDKHVFSGMENAVCLDLSYNYMSQALRRG 530 FKRQICSKSLYFDLSQNN I PWLNASTFRGMDRVACVDLSYNYISQTLNGH 527 FMDRCKNFKFTMDLSRNNLVTIKPEMFVNLSRLQCLSLSHNSIAQAVNGS 516

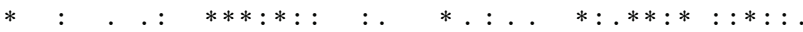

LRR8 QFNGLDSLVLLNLSYNRLDLYYDAAFSELNTTLKVLDISNNEFHFKMRGM 550 QFNGLDSLVLLNLSYNRLDLYYDAAFSELNTTLKVLDISNNEFHFKMRGM 580 QFSHLSKLSYLNMAYNRIDLYSDKAFQEVSGTLKALDLSNNEFHFIMKGM 577 QFLPLTNLQVLDLSHNKLDLYHWKSFSELP-QLQALDLSYNSQPFSMKGI 565 $* * \quad * . * \quad * *::: *:: * * * \quad: * . * * \quad *: . * *: * * . \quad * * * *$ :

(a)

Figure 1: Continued. 
Cobia TLR9 isoform $\mathrm{B}$ Cobia TLR9 isoform A Zebrafish TLR9

Mouse TLR9

Cobia TLR9 isoform B Cobia TLR9 isoform A Zebrafish TLR9

Mouse TLR9

Cobia TLR9 isoform B Cobia TLR9 isoform A Zebrafish TLR9

Mouse TLR9

Cobia TLR9 isoform B Cobia TLR9 isoform A Zebrafish TLR9

Mouse TLR9

Cobia TLR9 isoform B Cobia TLR9 isoform A Zebrafish TLR9 Mouse TLR9

Cobia TLR9 isoform B Cobia TLR9 isoform A Zebrafish TLR9

Mouse TLR9

Cobia TLR9 isoform B Cobia TLR9 isoform A Zebrafish TLR9 Mouse TLR9

Cobia TLR9 isoform B Cobia TLR9 isoform A Zebrafish TLR9 Mouse TLR9

Cobia TLR9 isoform B Cobia TLR9 isoform A Zebrafish TLR9 Mouse TLR9

Cobia TLR9 isoform B Cobia TLR9 isoform A Zebrafish TLR9 Mouse TLR9
LRR9

GHRFEF IQHLTNLEVLSLANNDIEMR IDQRL ISSSLKYLYFYGNHLDIMW 600 GHRFEF IQHLTNLEVLSLANND I EMR IDQRL ISSSLKYLYFYGNHLDIMW 630 GHQFTFLTHMS SL I ILSLANNH I GLR I SN ILTSASLKYL IFSGNRLDILW 627 GHNFSFVTHLSMLQSLSLAHNDIHTRVSSHLNSNSVRFLDFSGNGMGRMW 615 **.**:*:: * ****:*.* *:.. ****:::****:: :*

LRR10

LRR11

ASDNNKYTSFFQNLTNL I YLD ISNNGLMSVSSQVLRNLPGSIKALSISRN 650 ASDNNKYTSFFQNLTNLIYLDISNNGLMSVSSQVLRNLPGSIKALSISRN 680 DSWRNQY INLFQGLTNLTHLDISENQLKSLSPEVIVNLPLSLQVLRVDFN 677 GGLYLHFFQGLSGLLKLDLSQNNLH ILRPQNLDNLPKSLKLLSLRDN 664

LRR11 $\quad: * * * * * * \quad * * * *$

LLNYFPWKNMS ALSNLCHLNLSQNHLSYLPHIDSDN - - - - - LKFYDDKI 694 LLNYFPWKNMS ALSNLCHLNLSQNHLSYLPHIVTDFGANFSLLDLSHNRL 730 MLTYFPWANISVLQKLCYLNLSSNMLSYLPNINFELRLTG- - LDLSHNRL 725 YLSFFNWTSLSFLPNLEVLDLAGNQLKALTNGTLPNGTLLQKLDVSSNSI 714

$* .: * * .: * *: * \quad *: *: * *$ * * * : $\quad * \ldots:$ :

SESFVQIDRLTVDTKHFGVFHLSVTNVFDKHIPLVTHTKC- - - - - - - 734 GFIPEDFFKKAESLQYLYLNHNQIKELKHQYLPAPFKNSS - - - - - - - 770 VAIPKVFLSQAANLKNLNLNNNQLK ILDVQALPLPFHKGCTFIPGGQHKN 775 VSVVPAFFALA VELKEVNLSHN ILKTVDRSWFGP IVMNLT - . . . . . . . - 754 : $:$. : . : : : : : : . :

LRRCT

- STDVFNMETNPFKCDCDTSWFADFLLSTPVQIPYLSTHLHCEYPESQQG 783 - ALQLLTLHANPFKCDCDTSWFADFLLSTPVQIPYLSTHLHCEYPESQQG 819 RSSCKLVLHANPFTCSCVISGFAKFLRETDLDVPHLTTQVHCGFPESLAG 825 - - - VLDVRSNPLHCACG - AAFVDLLLEVQTKVPGLANGVKCGSPGQLQG 799

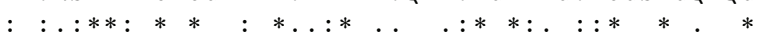

HN ILSMDQRSCQ - IYGSLAFLVCSILAVTF-TVLVTDYLIY--VLKTCKY 829 HN I LSMDQRSCQD I Y GSLAFLVCS ILAVTF-TVLPLLKHLYGWDMWYCLQ 868 VNVLSVDLRSCQEIFGGVAFLCTSLLTLAA - TCVPLLKHLYGWDLWYLIQ 874 RSIFAQDLRLCLDEVLSWDCFGLSLLAVAVGMVVPILHHLCGWDVWYCFH 849 .$:: *_{*} * \quad$. $\quad *: *::: \quad: \quad: \quad$ :

TIR

LFFIQDCILFDLCLIFFYWIFIIFCLFLFFGPLLAFVVFDTRNQAVRDWV 879 VLWAGHKGYSQLAGTDSQHHYVCFCHYD - - - - - AFVVFDTRNQAVRDWV 912 ILWTGHRGHTPANGNPTDTQYD - - . - . - . - AFVVFDTSNKAVRDWI 912 LCLAWLPLLARSRRSAQTLPYD - . - . . . . - AFVVFDKAQSAVADWV 887 : $\quad: \quad \operatorname{TIR} * * * * *$. : $* * * *$ : YNELTVNLENS - NHRRFYLCLEERDW IPGLSCIENLHNAVYNSVKTVFVL 928 YNELTVNLENS - NHRRFY YCLEERDW IPGLSCIENLHNAVYNSVKTVFVL 961 YKEMLVRLENR - GRWRF QLCLEERDW IPGVSCIENLHKSVYSSRKTVFVL 961 YNELRVRLEERRGRRALRLCLEDRDWLPGQTLFENLWASIYGSRKTLFVL 937 $*: *: * . * *: \quad .: \quad: * * * *: * * *: * *::: * * * \quad:: * . * * *: * * *$ SSGSDSGETVNGVIRQAFFMETVQQRLLDEKVDAAVLVLLGELFPKLKYL 978 SSGSDSGETVNGVIRQAFFM - - VQQRLLDEKVDAAVLVLLGELFPKLKYL 1009 TSPGGYSDAS-GIVRQAFLL - - VQQRLLDEKVDVAVLVLLDFLFPKFKYL 1008 AHT - - - DRVSGLLRTSFLL - - AQQRLLEDRKDVVVLVILRPDAHRSRYV 981 $: \quad: \quad *:: *: *:: \operatorname{TIR}^{*} * * * *::: * \ldots * * * * \quad:: *:$ QLRKRLCRRSVLSWPRNPRAQPLFWNKMETR - . - . - . . - . - . - - 1009 QLRKRLCRKSVLSWPRNPRAQPLFWNKMRI ALSSDNLK - - - . - . - - - 1047 QMRKRLCKKSVLSWPRNPRVQPLFWNDLRVALVSDNVRAYNKNVTESFF- 1057 RLRQRLCRQSVLFWPQQPNGQGGFWAQLSTALTRDNRHFYNQNFCRGPTA 1031 $:: *: * * *:: * * * * *:: * . * * * \quad .:$

E 1032

(b)

FIGURE 1: Amino acid sequence alignment of cobia (Rachycentron canadum) TLR9 isoform B deduced protein to cobia TLR9 (Rachycentron canadum, AGD79973.2), zebrafish TLR9 (Danio rerio, NP_001124066), and mouse TLR9 (Mus musculus, NP_112455.2). LRR, LRRTYP , and LRRCT domains are indicated with bold letters shaded with yellow accent; transmembrane domains are bold and underlined. CXXC motifs are indicated by black box; highly conserved motifs in TIR domains are double underlined. - - - - Sequence gaps, * identical residues,: conserved substitution, and. semiconserved substitution. 


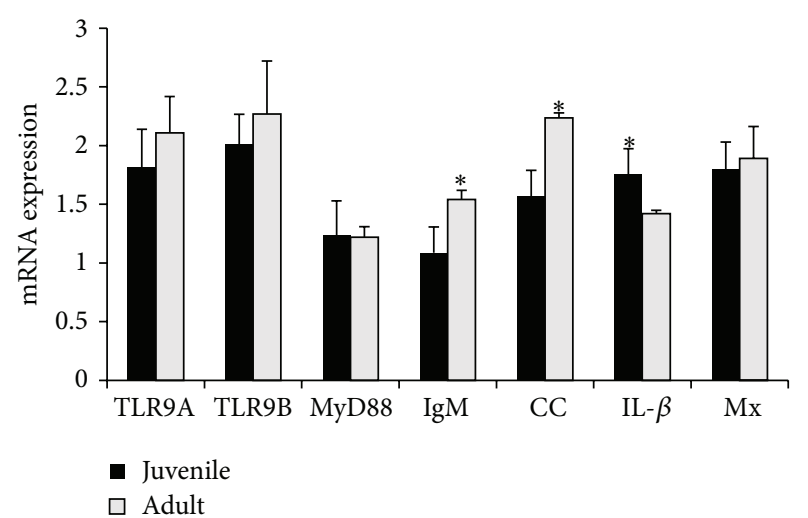

FIGURE 2: Quantitative analyses of toll-like receptor 9 and immunerelated gene expression in intestine of juvenile and adult. The relative expression variance is showed as ratio (the amount of gene mRNA expression normalized to the corresponding beta actin values). Data are shown as mean $\pm \mathrm{SD}(n=2)$. The significant difference is indicted with asterisk $(*)$ in the figure.

and analysis were conducted using the sequence detection software (SDS version 2.1. Applied Biosystems). The $2^{-\Delta \Delta C T}$ method was chosen as the calculation method [36]. The difference between the cycle threshold $(\mathrm{Ct})$ value of the target gene and the reference gene ( $\beta$-actin) called $\Delta \mathrm{CT}$ was calculated. $\Delta \Delta \mathrm{CT}=(\Delta \mathrm{CT}$ of target gene or PBS-injected group for the target gene at each time point $)-(\Delta \mathrm{CT}$ of the initial control).

2.7. Statistical Analysis. Data were analyzed using the SPSS16 (SPSS Inc., Chicago IL). Data distribution was determined using descriptive statistics. Differences in the means among the treatments were analyzed using ANOVA and compared using post hoc multiple comparison using Duncan's multiple range test. A $P$ value of $<0.05$ was considered significant.

\section{Results}

3.1. Cloning of Cobia TLR9 Isoform B. The full length of RCTLR9B (KF963251) was 3113 bp encoding 1009 amino acid residues. The RCTLR9B protein is homologous to Rachycentron canadum isoform A (AGD79973), Larimichthys crocea isoform A (ACF60624), Epinephelus coioides isoform A (ACV04893), and Dentex tumifrons (ABY79218) at 89\%, 66\%, $65 \%$, and $64 \%$, respectively. A signal peptide located at the 129 position of amino acid sequence was identified. In addition, 12 leucine repeats (LRR), LRRTYP (typical), LRRCT (LRR C-terminal), and a 244 amino acid Toll-interleukin1 receptor (TIR) domain in RCTLR9B were observed. The CXXC motif involved in ligand binding was identified on the LRR motif region at 209-223 amino acid segment containing two conserved motifs separated by six amino acid residues (Figure 1, indicted by a box). Three subsections of TIR domain known to be important in signaling and receptor localization were conserved in RCTLR9A, zebrafish, and mouse TLR9 (Figure 1).
3.2. Immune Genes Expression in Juvenile and Adult Intestine. The mRNA expressions of TLR9 isoform A and B, MyD88, IL$1 \beta$, IgM, chemokine, and $\mathrm{Mx}$ were examined in juvenile and adult cobia (Figure 2). The expressions of IgM and chemokine genes in the adult are significantly $(P<0.05)$ higher than those in the juvenile. The level of IL- $1 \beta$ was higher in the juvenile when compared to that in the adult. The expressions of TLR9 A and B isoforms, MyD88, and Mx were not significantly different between the juvenile and the adult.

\subsection{The Expression of Immune Genes in the Intestine after the Stimulation of $C P G$ ODNs}

3.3.1. TLR 9 A. After CpG ODN 1668 injection, RCTLR9A transcript increased significantly $(P<0.05)$ after $3 \mathrm{dpi}$, decreased to the lowest level at $6 \mathrm{dpi}$, and subsequently increased at 10 dpi (Figure 3(a)). While after CpG ODN 2395 injection, the expression bottomed after $3 \mathrm{dpi}$ and sharply peaked at $6 \mathrm{dpi}$. Among different ODNs, CpG ODN 2395 resulted in the highest fold change of RCTLR9A mRNA in comparison with those of CpG ODN 1668 and CpG ODN 2137.

3.3.2. TLR 9 B. No significant difference of expression was shown in CpG ODN 1668 ODN treated group at 1 dpi (Figure 3(b)). The expression peaked at $6 \mathrm{dpi}$ and later reduced to the lowest. However, the level of RCTLR9B with CpG ODN 2395 stimulation was found to be significantly higher at $6 \mathrm{dpi}$.

3.3.3. MyD88 Expression. After injection with CpG ODN 1668, the level of MyD88 transcript increased after 1 dpi and peaked at $3 \mathrm{dpi}$ and then reduced to the lowest at $6 \mathrm{dpi}$ and slightly increased at $10 \mathrm{dpi}$. Significant differences were found at 3 and $6 \mathrm{dpi}$ (Figure 3(c)). The level of MyD88 transcript after injection with CpG ODN 2395 continually increased after $3 \mathrm{dpi}$, peaked at $6 \mathrm{dpi}$, and then sharply bottomed at $10 \mathrm{dpi}$.

3.3.4. Mx Expression. CpG ODNs 1668 being a class B did not induce high fold change of Mx expression in intestine (Figure 4(a)). However, stimulation with CpG ODNs 2395 has induced significant high expression at $1 \mathrm{dpi}$ and at $3 \mathrm{dpi}$ the expression decreased and later it increased significantly higher at $6 \mathrm{dpi}$ and reduced to the lowest at $10 \mathrm{dpi}$.

3.3.5. IgM Expression. After CpG ODN 1668 stimulation, IgM transcription peaked at $1 \mathrm{dpi}$ and then decreased at $3 \mathrm{dpi}$ and reached the lowest level at $10 \mathrm{dpi}$ (Figure 4(b)), while the level of IgM transcript with CpG ODN 2395 stimulation increased after $1 \mathrm{dpi}$ and reached the highest level at $3 \mathrm{dpi}$ and sharply reduced at $6 \mathrm{dpi}$.

3.3.6. Chemokine CC Expression. CpG ODN 1668 has resulted significantly in the increase of chemokine CC and peaked at $3 \mathrm{dpi}$ and then the expression decreased at $6 \mathrm{dpi}$ 


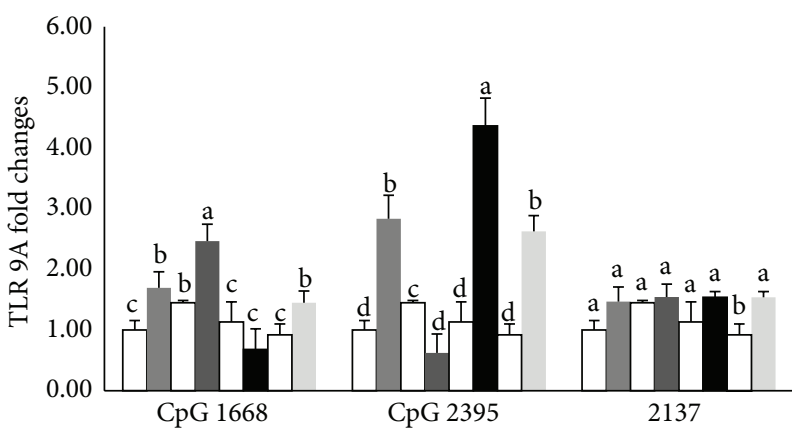

(a)

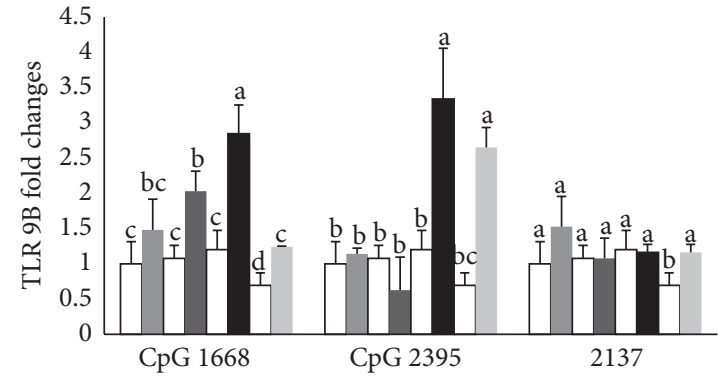

(b)

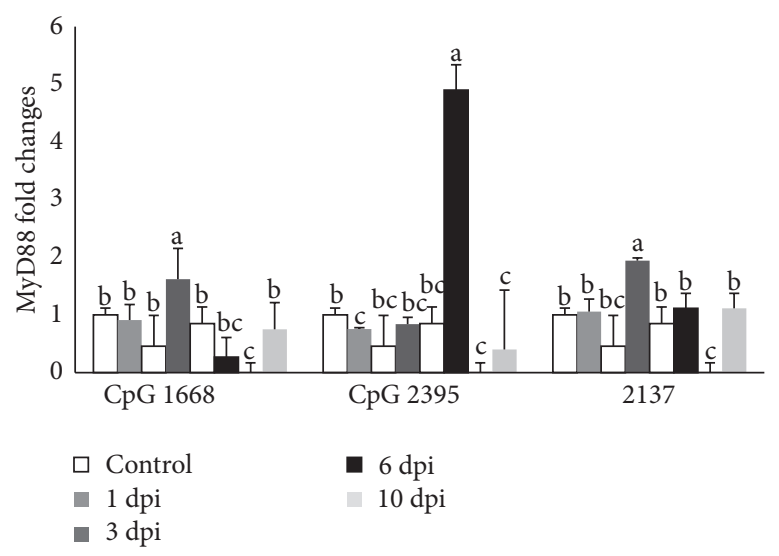

(c)

Figure 3: The relative mRNA expressions of TLR 9A (a); TLR 9B (b); and MyD88 (c) in cobia intestine after stimulating with different CpG ODNs $(1668,2395)$ and ODN 2137 as control measured by quantitative real-tie PCR at 1, 3, 6, and 10 days after stimulation. The expression values represented as "fold change" were compared to the noninjected control samples and $\beta$-actin was used as a reference gene. The results are presented as the mean $\pm \mathrm{SD}(n=2)$ and mean values with different alphabetical letters are significantly different $(P \leq 0.05)$.

after injection (Figure 4(c)). The level of chemokine transcript after injection with CpG ODN 2395 bottomed at 3 dpi and reached the highest level at $6 \mathrm{dpi}$ and then dropped at $10 \mathrm{dpi}$.

3.3.7. IL-1 $\beta$ Expression. Expression profile of IL- $1 \beta$ in intestine with CpG ODNs 1668 resulted in constant increase after $3 \mathrm{dpi}$ and peaked at $6 \mathrm{dpi}$; later the expression decreased at 10 dpi (Figure 4(d)). However for CpG ODN 2395 stimulation showed the expression bottomed after $3 \mathrm{dpi}$ and peaked significantly higher at $6 \mathrm{dpi}$ and decreased to the lowest at 10 dpi.

3.4. Protection Efficiency of CPG ODNs in Cobia against Bacterial Challenge. Experiment was conducted to determine whether CpG ODN injected cobia can be protected against bacterial challenge. Results revealed that CpG ODN 1668 and 2395 can protect cobia when challenged with Photobacterium damselae subsp. piscicida (Figure 5). Fish injected with PBs alone and injected with CpG ODN 2137 began to die at 3 days and 5 days after challenge. Fish injected with PBS showed $90 \%$ mortality within 10 days. Among the CpG ODN injected groups, the highest mortality was observed in CpG ODN 2137.
The highest survival rate was obtained from CpG ODN 1668 (90\%) and followed by CpG ODN 2395 (70\%).

\subsection{The Adjuvanticity of CPG ODNs}

3.5.1. TLR 9 Isoform A and B Expressions. Both RCTLR9 A and $\mathrm{B}$ expressions increased at $1 \mathrm{dpi}(\sim 9$ and 8 folds) and decreased at 3 dpi after i.p injection of FKB + alum + CpG 1668 (Figures 6(a) and 6(b)). Thereafter, both isoforms A and B increased at $6 \mathrm{dpi}$ ( $\sim 38$ and 42 folds). Expression of isoform A increased at $10 \mathrm{dpi}$ ( $\sim 51$ folds), in contrast, isoform $\mathrm{B}$ decreased ( $\sim 33$ folds) during the same time. Expressions of RCTLR 9A and B after being administrated with FKB + alum + CpG 2395 increased significantly until at 6 dpi $(\sim 27$ and 26 folds) and then decreased at $10 \mathrm{dpi}$. In control treatment with FKB + alum + 2137, expression of RCTLR9B increased significantly ( $\sim 5$ folds) until at $6 \mathrm{dpi}$ and then decreased at 10 dpi.

3.5.2. MyD88 Expression. Figure 6(c) showed that after administration the expression of Myd88 was fluctuated both in FKB + alum + CpG 1668 and in FKB + alum + CpG 2395. The expression of MyD88 decreased from 1 dpi to $3 \mathrm{dpi}$ and increased significantly at $6 \mathrm{dpi}$ in both CpG-ODN 1668 


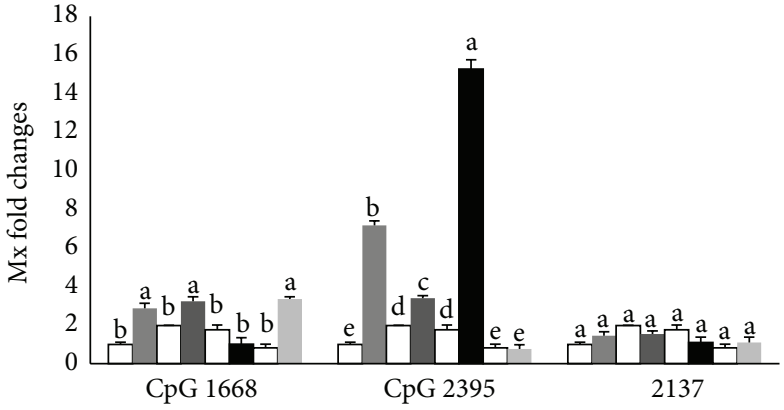

(a)

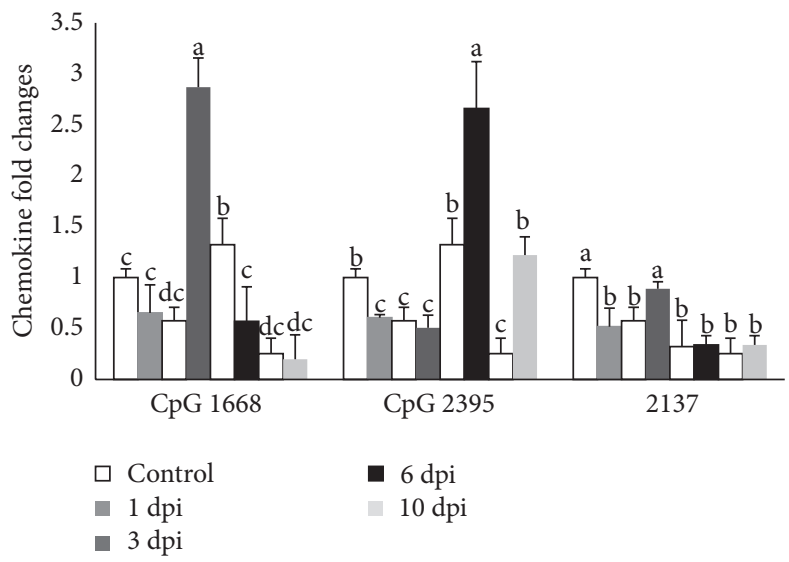

(c)

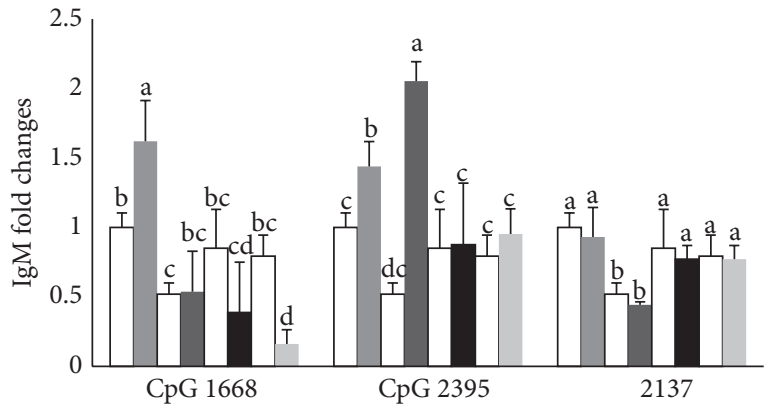

(b)

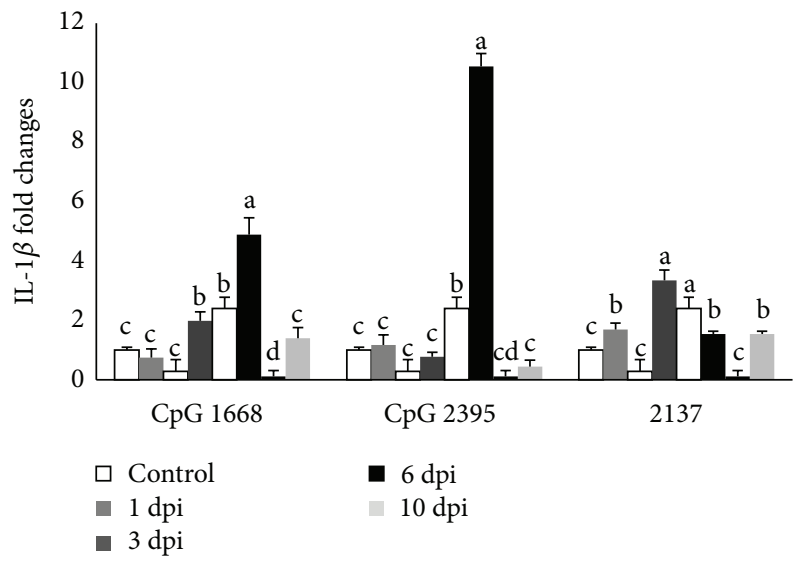

(d)

Figure 4: The relative mRNA expressions of Mx (a); IgM (b); CC (c); and interleukin 1- $\beta$ (d) in cobia intestine after stimulating with different CpG ODNs $(1668,2395)$ and ODN 2137 as control measured by quantitative real-tie PCR at 1, 3, 6, and 10 days after stimulation. The expression values are represented as "fold change" and compared to the noninjected control samples and $\beta$-actin was used as a reference gene. The results are presented as the mean $\pm \mathrm{SD}(n=2)$ and mean values with different letters are significantly different $(P \leq 0.05)$.

and CpG-ODN 2395 ( $\sim 10$ and 22 folds) but then decreased and reached the lowest level $(\sim 1$ fold) at $10 \mathrm{dpi}$. In control group FKB + alum + 2137, profile of MyD88 showed fluctuated expression. The expression decreased at $3 \mathrm{dpi}$, increased at $6 \mathrm{dpi}$, and bottomed at $10 \mathrm{dpi}$. FKB + alum + CpG 2395 group showed the highest fold changes compared with the other treatment.

3.5.3. IL-1 $\beta$ Expression. IL-1 $\beta$ expressed low in all three treatments $(\mathrm{FKB}+$ alum + CpG 1668; FKB + alum + CpG 2395; and $\mathrm{FKB}+$ alum +2137 treatments) in terms of fold changes. The expression profile of IL-1 $\beta$ in both FKB + alum + CpG 1668 and FKB + alum + CpG 2395 became significantly low after $3 \mathrm{dpi}$. The expression profile of the control group was higher than that of the treatment group in most of observation time (Figure 6(d)). Only at $6 \mathrm{dpi}$, treatment group showed an increase in expression. In control 2137 group, the expression profile of IL- $1 \beta$ showed fluctuation of no significant difference.

3.6. Histological Observation. Normal gross morphology on the intestinal wall of cobia was examined using light microscopy (LM) after hematoxylin and eosin ( $\mathrm{H}$ and $\mathrm{E})$ staining in all groups. No inflammatory cells were found in the lamina propria of the cobia intestine. Additionally, fish from the control group showed an intestinal epithelium consisting of a single layer of columnar epithelial cells with abundant goblet cells joined by apparently intact junctional complexes (Figures 7 and 8). No cell debris was observed in the gut lumen. A continuous mucus layer was evident over the apical surface of the cells. No signs of damage, edema, or inflammation were observed.

\section{Discussion}

RCTLR9B has a transmembrane domain, indicating its localization at the endosomal membrane. The CLUSTALW alignment of cobia (RCTLR9B and RCTLR9A), zebrafish, and mouse TLR9 showed high homology according to the amino acid sequence (Figure 1). Motifs in the cDNA sequence have been proposed to bind to the PAMPs of TLR9 [37]. Our results demonstrated that RCTLR9B has CXXC motifs between 209 and 223 amino acids, suggesting its binding nature to the ligand. In human, five isoforms of TLR9 have been reported (TLR9A-E) [14]. Differential localizations of these TLR9 isoforms in various cells types raise the question of functional significance of computational modeling, 
structure, and biological relevance a specific isoform may play during inflammation. TLR9 A, C, D, and E are confirmed to be predicted to be located on the ER, but TLR9 B, on the other hand, is located on mitochondria [14]. In teleost, yet only two TLR9 isoforms have been identified in sea bream [10] and croaker [17]. However, the cellular localization of these isoforms in teleost has not been studied.

Both RCTLR9A and RCTLR9B were expressed at a similar level in healthy juvenile and adult cobia. No significant differences in expressions were found between RCTLR9A and RCTLRB or between the juvenile and the adult. This is in agreement with a previous study, in which both TRL9 isoforms were found in the intestine of healthy Sparus aurata [10]. However, in juvenile croaker the expression of TLR9B was significantly higher than that of TLR9A [17]. In addition, the expressions of MyD88 and Mx were not significantly different between the juvenile and the adult. Similar levels of expressions were observed in the intestine of healthy rohu [38]. The mRNA expressions of IgM and chemokine CC were significantly higher in adult cobia when compared to juvenile cobia. The basal expressions of CXC and chemokine CC were detected in pig jejunum, caecum, and colon before the treatment of CpG ODNs [24]. The higher expressions of IgM and chemokine $\mathrm{CC}$ in adults may indicate the more activated immunity due to the increased exposure to pathogens.

Since the GI tract is the major portal of entry for pathogens $[32,33]$, it would be meaningful to investigate the expression of genes related to immunity in response to the administration of $\mathrm{CpG}$ ODNs in the cobia intestine. The cobia intestinal epithelial cell line is not available; we therefore intraperitoneally injected various CpG ODNs to the fish and acquired intestinal tissues at different time points. Results demonstrated that intraperitoneal stimulation of CpG ODNs had an influence on the expression of genes related to innate immunity in the cobia intestine. The expression of immunityrelated genes in the intestine was found to be dependent on the type of CpG ODNs and the time, namely, day after injection (dpi). Fish injected with CpG ODN 2395 had significantly increased expressions of both RCTLR9A and RCTLR9B at 6 dpi, which was reflected on the significantly upregulated expression of MyD88 in comparison with that of fish injected with CpG ODN 1668. A human epithelial cell line, HT-29, was found to spontaneously express TLR9 mRNA and protein, and stimulation with CpG ODNs and bacterial DNA induced the expression of proinflammatory cytokine, including IL- $1 \beta$ and IL-8 $[39,40]$. In the present study, the expression of IL- $1 \beta$ remained unchanged at 1 and $3 \mathrm{dpi}$, peaked at $6 \mathrm{dpi}$, and returned to the baseline at $10 \mathrm{dpi}$. The delayed IL- $1 \beta$ response may be due to the following reasons: (1) the activation of TLR9 by CpG ODNs does not always lead to immediate upregulation of an inflammatory cytokine and (2) the presence of TLR9 receptor-ligand interactions leads to intestinal homeostasis which results in the delayed response of inflammatory cytokines [41]. Further investigations would be required to elucidate the relationship between TLR9 and elicited inflammatory responses after the stimulation of CpG ODNs in the cobia intestine.

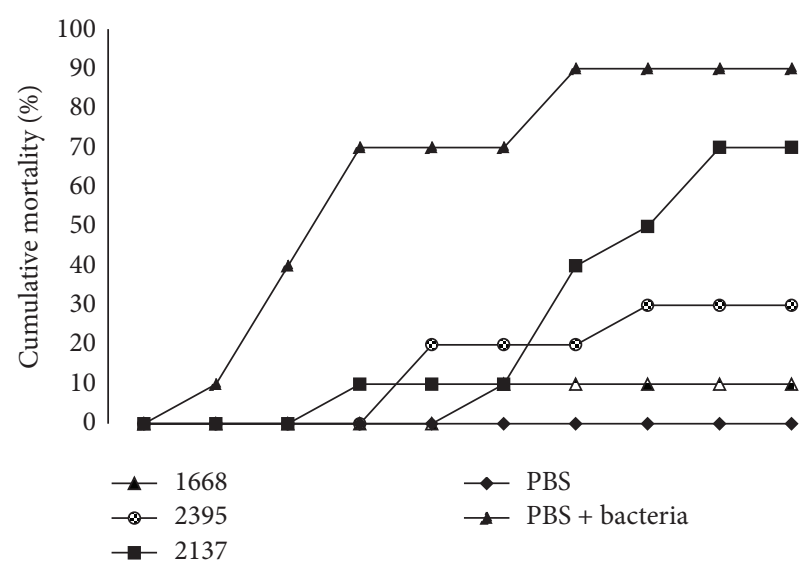

FIGURE 5: Cumulative percent mortalities of fish injected intraperitoneally (i.p) with $100 \mu \mathrm{L}$ PBS alone, PBS alone with bacterial challenge, CpG ODN 1668, 2395, and control ODN 2137. After $48 \mathrm{~h}$ after CpG ODN injection, cobia was i.p. injected with $50 \mu \mathrm{L}$ of $3.25 \times$ $10^{6}$ bacteria (Photobacterium damselae subsp. piscicida). The group injected with ODN 2395 and 1668 displayed lower mortalities than any other group, $n=10$ fish per group.

In response to the stimulation of CpG ODNs, the activated $\mathrm{T}$ helper cells draft immunocompetent cells into the intestinal mucosa and influence the chemokines secreted by immune cells, such as macrophages, activated NK cells, and T cells, which determine the subsequent Th1/Th2 immune responses $[42,43]$. Intraperitoneal injection of CpG ODN 1668 and 2395 significantly increased the mRNA expression of chemokine CC in the cobia intestine at $3 \mathrm{dpi}$ and $6 \mathrm{dpi}$, respectively, which might be due to the engagement of immune cells with Th1 type property to the intestinal mucosa after the injection of $\mathrm{CpG}$ ODNs. In the piglets administered with CpG ODN D19, the percentage of macrophages and dendritic cells, as well as the expression of chemokine CC, in the intestinal tissue was significantly elevated [24].

CpG ODN 1668 is recognized as a potential immunostimulant for Atlantic salmon, common carp, and Japanese flounder [44-46]. In this study, a CpG ODN other than CpG ODN 1668 and CpG ODN 2395 (a class C CpG ODN) also showed protective effects and significantly increased the survival rate of cobia challenged with live $P$. damselae subsp. piscicida. Similar results found that olive flounder injected with CpG ODN 1668 and 2395 had the highest survival rate against $M$. avidus and $E$. tarda infection, respectively $[47,48]$. In the mouse model, administration of CpG ODNs alone has been demonstrated to increase the resistance to listeriosis [49] and Helicobacter pylori infection [50]. Oral administration of CpG ODNs protected (90\%) newborn mice from Cryptosporidium parvum enteric infection [23, 51]. It is difficult to accurately analyze the linkage between the cytokine level and survival rate in aquatic species because only very limited information is available in the literatures. In the present study, the expressions of chemokine CC and IL- $1 \beta$ were significantly increased in cobia injected with $\mathrm{CpG}$ ODNs. Whether the significantly increased survival rate in cobia injected with CpG ODN 1668 and 2395 was due to upregulated expression of cytokines needs to be confirmed in 


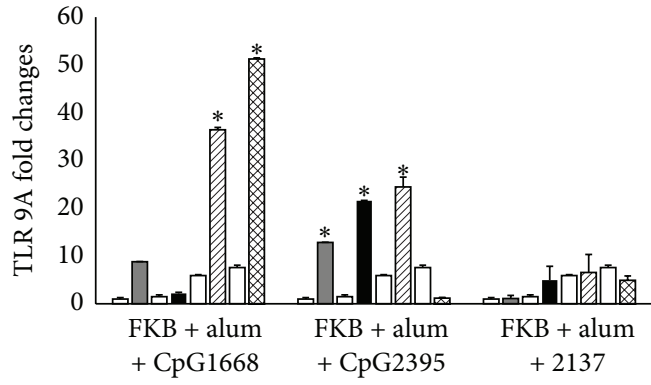

(a)

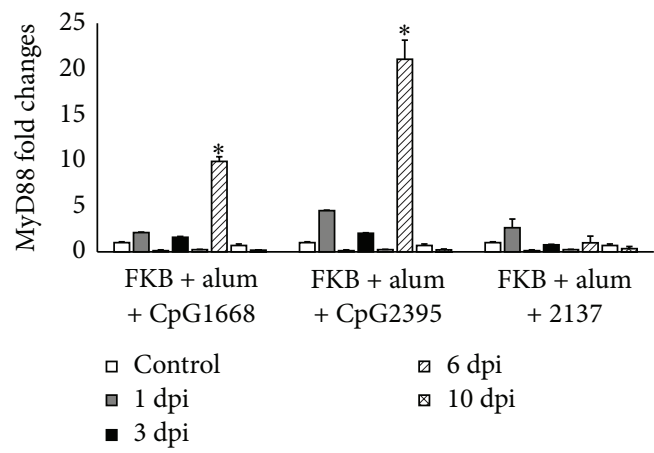

(c)

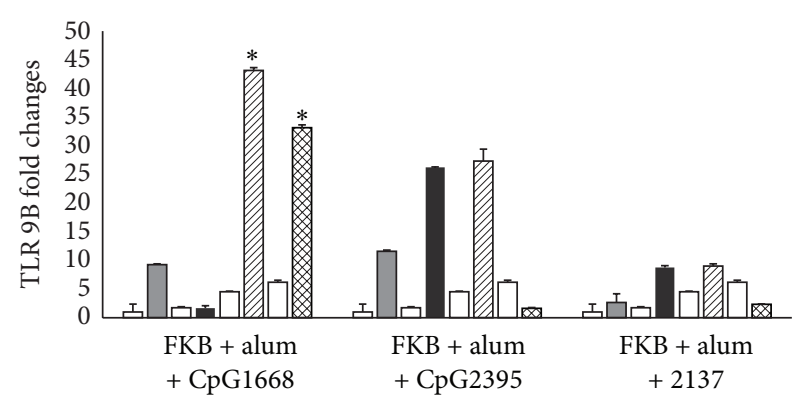

(b)

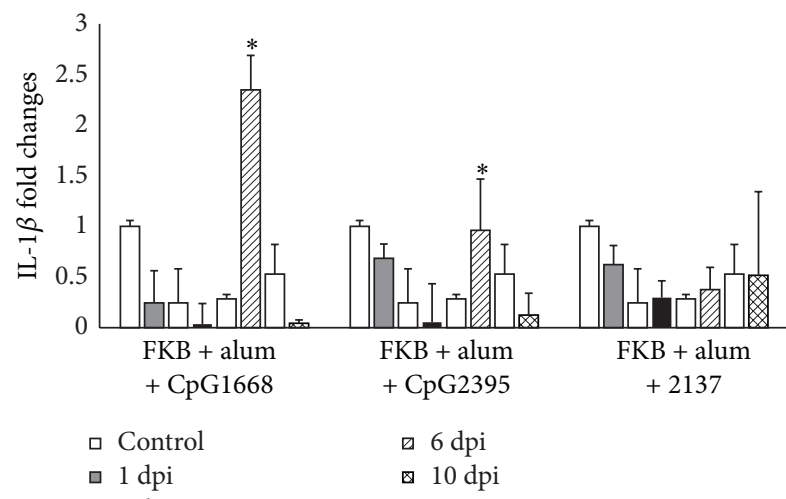

(d)

FIgURE 6: The relative mRNA expressions of (a) TLR9 A, (b) TLR9 B, (c) MyD88, and (d) IL-1 $\beta$ in the posterior cobia intestine stimulated with formalin-killed vaccine mixed with $\mathrm{CpG}$ and alum and PBS-injected and measured by quantitative real-time PCR. The sampling was carried out at $1,3,6$, and 10 days after stimulation and $\beta$-actin was used as a reference gene. The results are presented as the mean \pm SD $(n=2)$ and mean values with asterisk $(*)$ are significantly different $(P \leq 0.05)$.

the future study. However, it has been reported that excessive activation of the immune system with overwhelming production of proinflammatory cytokines can be harmful leading to microcirculatory dysfunction, tissue damage, shock, or even death in severe cases [52]. Moreover, different types of CpG ODNs can elicit different immune responses, for example, the profile of upregulated genes. CpG ODN 2395, being a C-class CpG ODNs, is intermediate between A-class and B-class CpG ODNs in terms of the immunostimulatory activity [53]. The presence of CpG motifs at the $5^{\prime}$-end of CClass ODN is necessary for inducing strong interferon (IFN)$\alpha$ production [54]. In this region of the CpG ODNs, the required sequence appeared to be similar to that of the B-class CpG ODNs, where the presence of a $5^{\prime}$-TCG is very critical to the immunostimulatory effects [55].

The effect of CpG ODNs on the adaptive immunity of cobia was also explored in the present study. Formulation of CpG ODNs as the adjuvant to enhance the immunogenicity of vaccines has been extensively studied in mice, rabbits, and cattle [56-59]. The combination of FKB, alum, and CpG ODNs (either 1668 or 2395) significantly enhanced the expressions of RCTLR9A and RCTLR9B when compared to the control ODN 2137. Presumably, CpG ODNs initiated the signal transduction in endosomes where TLR9 is located [6062]. It is noteworthy that the increased expression of TLR9 ( $\sim 50$ folds) in cobia injected with CpG ODN 1688 formulated with alum and FKB was dramatically higher than that of cobia injected with CpG ODN 1688 ( $\sim 3$ folds) alone. This indicated that alum and bacterial antigen (FKB) stimulated the immune responses to upregulate the expression of TLR9, which may facilitate the uptake of the CpG ODNs. CpG ODNs and alum worked synergistically to enhance immune-potentiating and antigen-sparing effects of a vaccine against swine influenza virus [63], which was not observed when CpG ODNs or alum was used alone. The increased expressions ( $\sim 5$ folds) of RCTLR9A and RCTLR9B in cobia injected with the control ODN 213 formulated with alum and FKB may be attributed to the immunostimulatory effects of alum and FKB. In addition, ODNs on a phosphorothioate backbone without CpG motifs have been shown to nonspecifically stimulate TLR9-dependent or -independent activation [64, 65]. The increased expression of MyD88 at $6 \mathrm{dpi}$ implied that the Myd88-dependent signaling pathway of TLR9 was activated in response to CpG ODNs, because this was not seen in cobia injected with the control ODN 2137. The expression of IL-1 $\beta$, a proinflammatory cytokine, was significantly upregulated at $6 \mathrm{dpi}$ in cobia injected with the CpG ODNs, but not the control ODN, with alum and FKB. In a vaccination study on Japanese flounders, the transcription of IL- $1 \beta$ was significantly increased in both vaccinated and nonvaccinated groups at $1 \mathrm{dpi}$ indicating that the handling and injecting procedure during vaccination may induce inflammatory 


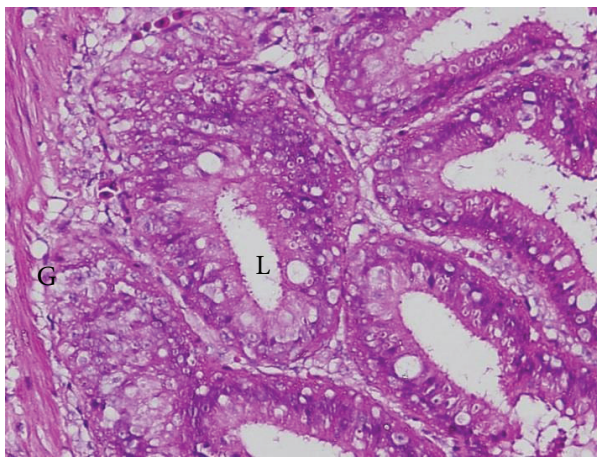

(a)

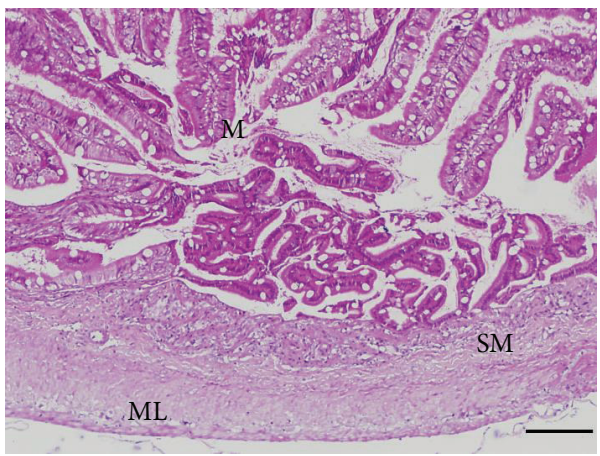

(c)

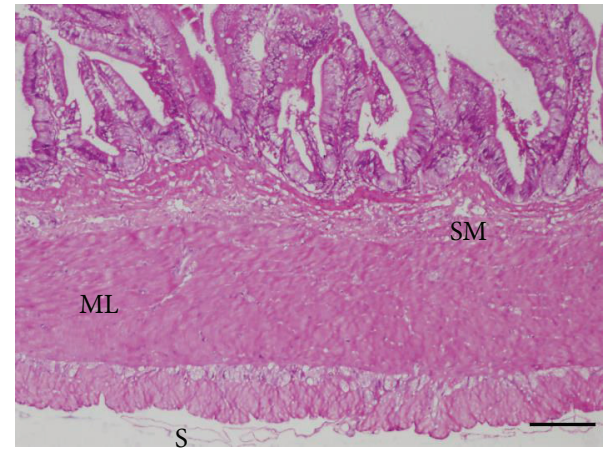

(b)

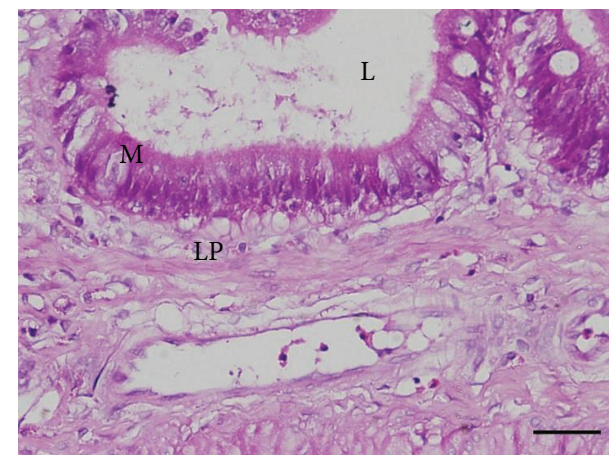

(d)

FIGURE 7: Histopathological observations in posterior part of cobia intestine injected with control PBS (i) and stimulation of cobia mixed with FKB, alum and 2137 (ii), 2395 (iii), and 1668 (iv) at 6 days after stimulation. Letters in the figure are denoted as M: mucosa epithelium, L: lumen, ML: muscular layer, SM: submucosa, LP: lamina propria, S: serosa, and G: goblet cells.

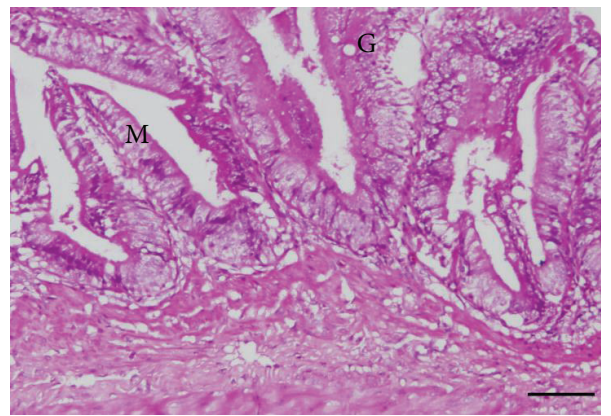

(a)

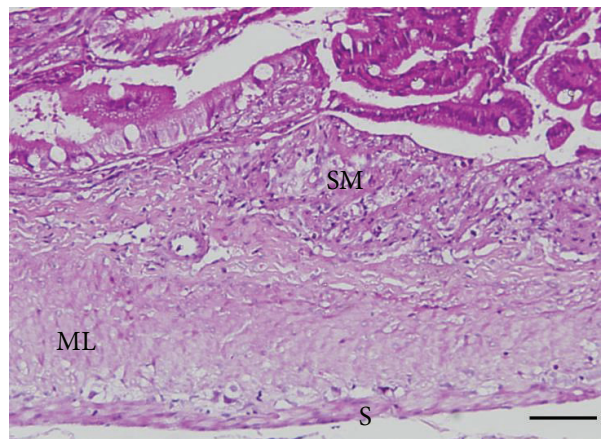

(c)

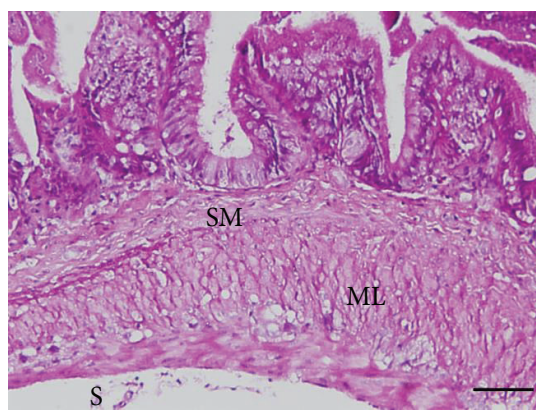

(b)

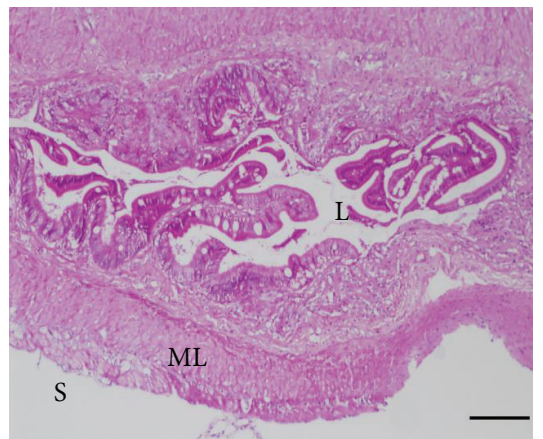

(d)

FIGURE 8: Histopathological observations in posterior part of cobia intestine injected with control PBS (i) and stimulation of cobia mixed with FKB, alum and 2137 (ii), 2395 (iii), and 1668 (iv) at 10 days after stimulation. Letters in the figure are denoted as M: mucosa epithelium, L: lumen, ML: muscular layer, SM: submucosa, LP: lamina propria, S: serosa, and G: goblet cells. 
responses temporally [66]. Although IL-1 $\beta$ has been indicated to upregulate during the course of infections in many mammals, the expression of IL- $1 \beta$ in the posterior distal intestine remained unchanged in rainbow trout infected with A. salmonicida [67]. In addition, the expression of IL- $1 \beta$ may be affected by the amount of antigens present in the posterior intestine of Atlantic cod [68].

Fish vaccines formulated with alum salts are generally accepted due to their safety and satisfactory immunostimulatory effects [69]. In olive flounders, the dosage at $500 \mu \mathrm{g}$ alum alone per fish only induced very mild inflammation without abnormal histopathological changes [70]. When the dosage was increased to $1600 \mu \mathrm{g}$ per fish, severe inflammation and mortality were observed. In the present study, only 45 $\mu \mathrm{g}$ alum was used in our vaccines. Moreover, addition of $10 \mu \mathrm{g}$ CpG ODNs to the vaccine formulation did not cause undesired side effects, such as lamina propria dilation and epithelial cell necrosis, at the site of injection as indicated by the histological observation.

\section{Conclusion}

The cobia TLR9B gene was cloned and ligand binding region CXXC motifs were found on the cobia TLR9B protein. Since TLR9 is the cellular receptor for CpG ODNs, the immunostimulatory effects of CpG ODNs in the intestine were investigated by intraperitoneal injection of various $\mathrm{CpG}$ ODNs to cobia fish. Results revealed that the expressions of RCTLR9 and proinflammatory chemokine genes were upregulated and were dependent on the type of CpG ODNs used. The CpG ODNs injected cobia also had significantly increased survival rates after challenge with live $P$. damselae subsp. Piscicida. Finally, the adjuvanticity of CpG ODNs was examined by formulating CpG ODNs as the adjuvant in a vaccine for cobia. The expressions of cobia TLR9, MyD88, and IL- $1 \beta$ were significantly elevated in cobia injected with CpG ODNs formulated with alum and FKB. No signs of tissue damage and overwhelming inflammatory responses were observed at the site of injection. Application of $\mathrm{CpG}$ ODNs may be used to increase the disease resistance and efficacy of vaccines in cobia.

\section{Conflict of Interests}

The authors declare that there is no conflict of interests regarding the publication of this paper.

\section{Acknowledgments}

The authors thank Dr. Stone Chen and Dr. Hso-Chi Chaung at Department of Veterinary Medicine and Graduate Institute of Animal Vaccine Technology, Dr. Winton Cheng at Department of Aquaculture, NPUST, and Dr. Jiin-Ju Guo at Tungkang Biotechnology Research Center, Pingtung, Taiwan, for their support and discussions during this study. They thank International Cooperation and Development Fund (ICDF), Taiwan, for granting scholarship to study doctoral degree.

\section{References}

[1] L. Gao, C. He, X. Liu et al., "The innate immune-related genes in catfish," International Journal of Molecular Sciences, vol. 13, no. 11, pp. 14172-14202, 2012.

[2] J. H. W. M. Rombout, L. Abelli, S. Picchietti, G. Scapigliati, and V. Kiron, "Teleost intestinal immunology," Fish and Shellfish Immunology, vol. 31, no. 5, pp. 616-626, 2011.

[3] R. A. Dalmo, K. Ingebrigtsen, and J. Bogwald, "Non-specific defence mechanisms in fish, with particular reference to the reticuloendothelial system (RES)," Journal of Fish Diseases, vol. 20, no. 4, pp. 241-273, 1997.

[4] C. M. Press and Ø. Evensen, "The morphology of the immune system in teleost fishes," Fish and Shellfish Immunology, vol. 9, no. 4, pp. 309-318, 1999.

[5] J. H. W. M. Rombout, A. J. Taverne-Thiele, and M. I. Villena, "The gut-associated lymphoid tissue (GALT) of carp (Cyprinus carpio L.): an immunocytochemical analysis," Developmental and Comparative Immunology, vol. 17, no. 1, pp. 55-66, 1993.

[6] J. Van Loo, "How chicory fructans contribute to zootechnical performance and well-being in livestock and companion animals," Journal of Nutrition, vol. 137, no. 11, 2007.

[7] S. Picchietti, L. Guerra, F. Bertoni et al., "Intestinal T cells of Dicentrarchus labrax (L.): gene expression and functional studies," Fish and Shellfish Immunology, vol. 30, no. 2, pp. 609617, 2011.

[8] D. B. Iliev, I. Skjæveland, and J. B. Jørgensen, "CpG oligonucleotides bind TLR9 and RRM-Containing proteins in Atlantic Salmon (Salmo salar)," BMC Immunology, vol. 14, no. 1, article 12, 2013.

[9] J. H. W. M. Rombout, A. A. van den Berg, C. T. G. A. van den Berg, P. Witte, and E. Egberts, "Immunological importance of the second gut segment of carp. III. Systemic and/or mucosal immune responses after immunization with soluble or particulate antigen," Journal of Fish Biology, vol. 35, no. 2, pp. 179-186, 1989.

[10] R. Franch, B. Cardazzo, J. Antonello, M. Castagnaro, T. Patarnello, and L. Bargelloni, "Full-length sequence and expression analysis of Toll-like receptor 9 in the gilthead seabream (Sparus aurata L.)," Gene, vol. 378, no. 1-2, pp. 42-51, 2006.

[11] Y. Palti, "Toll-like receptors in bony fish: from genomics to function," Developmental and Comparative Immunology, vol. 35, no. 12, pp. 1263-1272, 2011.

[12] E. Cario, "Bacterial interactions with cells of the intestinal mucosa: toll-like receptors and NOD2," Gut, vol. 54, no. 8, pp. 1182-1193, 2005.

[13] S. Uematsu and S. Akira, "Toll-like receptors and innate immunity," Journal of Molecular Medicine, vol. 84, no. 9, pp. 712725, 2006.

[14] K. J. McKelvey, J. Highton, and P. A. Hessian, "Cell-specific expression of TLR9 isoforms in inflammation," Journal of Autoimmunity, vol. 36, no. 1, pp. 76-86, 2011.

[15] M. Gürsel, D. Verthelyi, I. Gürsel, K. J. Ishii, and D. M. Klinman, "Differential and competitive activation of human immune cells by distinct classes of CpG oligodeoxynucleotide," Journal of Leukocyte Biology, vol. 71, no. 5, pp. 813-820, 2002.

[16] T. K. Mao, Z.-X. Lian, C. Selmi et al., "Altered monocyte responses to defined TLR ligands in patients with primary biliary cirrhosis," Hepatology, vol. 42, no. 4, pp. 802-808, 2005.

[17] C.-L. Yao, P. Kong, Z.-Y. Wang et al., "Cloning and expression analysis of two alternative splicing toll-like receptor 9 isoforms A and B in large yellow croaker, Pseudosciaena crocea," Fish and Shellfish Immunology, vol. 25, no. 5, pp. 648-656, 2008. 
[18] A. M. Krieg, "CpG motifs in bacterial DNA and their immune effects," Annual Review of Immunology, vol. 20, pp. 709-760, 2002.

[19] D. M. Klinman, D. Currie, I. Gursel, and D. Verthelyi, "Use of CpG oligodeoxynucleotides as immune adjuvants," Immunological Reviews, vol. 199, pp. 201-216, 2004.

[20] Z. Linghua, G. Yong, T. Xingshan, and Z. Fengzhen, "CpG oligodinucleotides induce strong humoral and cellular responses to swine streptococcic septicemia vaccine in piglets in vivo," International Immunopharmacology, vol. 6, no. 3, pp. 342-350, 2006.

[21] J. Vollmer, R. Weeratna, P. Payette et al., "Characterization of three CpG oligodeoxynucleotide classes with distinct immunostimulatory activities," European Journal of Immunology, vol. 34, no. 1, pp. 251-262, 2004.

[22] G. Hartmann, R. D. Weeratna, Z. K. Ballas et al., "Delineation of a CpG phosphorothioate oligodeoxynucleotide for activating primate immune responses in vitro and in vivo," Journal of Immunology, vol. 164, no. 3, pp. 1617-1624, 2000.

[23] S. Lacroix-Lamandé, N. Rochereau, R. Mancassola, M. Barrier, A. Clauzon, and F. Laurent, "Neonate intestinal immune response to CpG oligodeoxynucleotide stimulation," PLoS ONE, vol. 4, no. 12, Article ID e8291, 2009.

[24] Q. Cheng, C. Xu, L. Zhang, J. Li, T. Cao, and M. Zhang, "Administered CpG oligodeoxynucleotide induces mRNA expression of CXC and CC chemokines at the intestinal mucosa and PBMCs in piglets," International Immunopharmacology, vol. 10, no. 5, pp. 611-618, 2010.

[25] I. Skjæveland, D. B. Iliev, J. Zou, T. Jørgensen, and J. B. Jørgensen, "A TLR9 homolog that is up-regulated by IFN- $\gamma$ in Atlantic salmon (Salmo salar)," Developmental and Comparative Immunology, vol. 32, no. 6, pp. 603-607, 2008.

[26] A. Cuesta, I. Salinas, M. Á. Esteban, and J. Meseguer, "Unmethylated CpG motifs mimicking bacterial DNA triggers the local and systemic innate immune parameters and expression of immune-relevant genes in gilthead seabream," Fish and Shellfish Immunology, vol. 25, no. 5, pp. 617-624, 2008.

[27] C.-S. Liu, Y. Sun, Y.-H. Hu, and L. Sun, "Identification and analysis of a CpG motif that protects turbot (Scophthalmus maximus) against bacterial challenge and enhances vaccineinduced specific immunity," Vaccine, vol. 28, no. 25, pp. 41534161, 2010.

[28] C. F. Chang, J. H. Yang, and S. L. Chang, "Application of dietary $\beta$-1, 3-1, 6-glucan in enhancing resistance of cobia (Rachycentron canadum) against Photobacterium damselae subsp. piscicida and Streptococcus iniae infections," Journal of Taiwan Fisheries Research, vol. 14, pp. 75-87, 2006.

[29] C. Lopez, P. R. Rajan, J. H.-Y. Lin, T.-Y. Kuo, and H.-L. Yang, "Disease outbreak in seafarmed Cobia (Rachycentron canadum) associated with Vibrio Spp., Photobacterium damselae ssp. piscicida, monogenean and myxosporean parasites," Bulletin of the European Association of Fish Pathologists, vol. 22, no. 3, pp. 206-211, 2002.

[30] P.-C. Liu, J. I.-Y. Lin, and K.-K. Lee, "Virulence of Photobacterium damselae subsp. piscicida in cultured cobia Rachycentron canadum," Journal of Basic Microbiology, vol. 43, no. 6, pp. 499$507,2003$.

[31] S. C. Chen and C. Hsu, "Studies on the pathogenicity and pathology of Photobacterium damselae subsp. piscicida on Rachycentron canadum," Journal of The Fisheries Society of Taiwan, vol. 32, 4, 2005.

[32] B. Magariños, J. L. Romalde, M. Noya, J. L. Barja, and A. E. Toranzo, "Adherence and invasive capacities of the fish pathogen Pasteurella piscicida," FEMS Microbiology Letters, vol. 138, no. 1, pp. 29-34, 1996.

[33] M. V. López-Dóriga, A. C. Barnes, N. M. S. Dos Santos, and A. E. Ellis, "Invasion of fish epithelial cells by Photobacterium damselae suksp. piscicida: evidence for receptor specificity, and effect of capsule and serum," Microbiology, vol. 146, no. 1, pp. 21-30, 2000.

[34] G. Lu and E. N. Moriyama, "Vector NTI, a balanced all-in-one sequence analysis suite," Briefings in Bioinformatics, vol. 5, no. 4, pp. 378-388, 2004.

[35] S. R. M. Jones, M. D. Fast, S. C. Johnson, and D. B. Groman, "Differential rejection of salmon lice by pink and chum salmon: disease consequences and expression of proinflammatory genes," Diseases of Aquatic Organisms, vol. 75, no. 3, pp. 229-238, 2007.

[36] K. J. Livak and T. D. Schmittgen, "Analysis of relative gene expression data using real-time quantitative PCR and the 2$\Delta \Delta$ CT method," Methods, vol. 25, no. 4, pp. 402-408, 2001.

[37] J. K. Bell, G. E. D. Mullen, C. A. Leifer, A. Mazzoni, D. R. Davies, and D. M. Segal, "Leucine-rich repeats and pathogen recognition in Toll-like receptors," Trends in Immunology, vol. 24, no. 10, pp. 528-533, 2003.

[38] M. Basu, B. Swain, B. R. Sahoo, N. K. Maiti, and M. Samanta, "Induction of toll-like receptor (TLR) 2, and MyD88-dependent TLR-signaling in response to ligand stimulation and bacterial infections in the Indian major carp, mrigal (Cirrhinus mrigala)," Molecular Biology Reports, vol. 39, no. 5, pp. 6015-6028, 2012.

[39] L. Andresen, M. W. Matthiessen, J. Rask-Madsen, J. Brynskov, and G. Pedersen, "Expression of toll-like receptor 9 and response to bacterial cpg oligodeoxynucleotides in human intestinal epithelium," Clinical and Experimental Immunology, vol. 141, no. 2, pp. 298-306, 2005.

[40] J. B. Ewaschuk, J. L. Backer, T. A. Churchill, F. Obermeier, D. O. Krause, and K. L. Madsen, "Surface expression of tolllike receptor 9 is upregulated on intestinal epithelial cells in response to pathogenic bacterial DNA," Infection and Immunity, vol. 75, no. 5, pp. 2572-2579, 2007.

[41] S. Rakoff-Nahoum, J. Paglino, F. Eslami-Varzaneh, S. Edberg, and R. Medzhitov, "Recognition of commensal microflora by toll-like receptors is required for intestinal homeostasis," Cell, vol. 118, no. 2, pp. 229-241, 2004.

[42] D. D. Taub, K. Conlon, A. R. Lloyd, J. J. Oppenheim, and D. J. Kelvin, "Preferential migration of activated $\mathrm{CD} 4^{+}$and $\mathrm{CD}^{+} \mathrm{T}$ cells in response to MIP- $1 \alpha$ and MIP-I $\beta$," Science, vol. 260, no. 5106, pp. 355-358, 1993.

[43] M. Uguccioni, M. D’Apuzzo, M. Loetscher, B. Dewald, and M. Baggiolini, "Actions of the chemotactic cytokines MCP1 , MCP-2, MCP-3, RANTES, MIP- $1 \alpha$ and MIP- $1 \beta$ on human monocytes," European Journal of Immunology, vol. 25, no. 1, pp. 64-68, 1995.

[44] A. C. Carrington and C. J. Secombes, "A review of CpGs and their relevance to aquaculture," Veterinary Immunology and Immunopathology, vol. 112, no. 3-4, pp. 87-101, 2006.

[45] J. B. Jørgensen, J. Zou, A. Johansen, and C. J. Secombes, "Immunostimulatory $\mathrm{CpG}$ oligodeoxynucleotides stimulate expression of IL-1 $\beta$ and interferon-like cytokines in rainbow trout macrophages via a chloroquine-sensitive mechanism," Fish and Shellfish Immunology, vol. 11, no. 8, pp. 673-682, 2001.

[46] E. H. Lee and K. H. Kim, "CpG-ODN increases resistance of olive flounder (Paralichthys olivaceus) against Philasterides dicentrarchi (Ciliophora: Scuticociliatia) infection," Fish and Shellfish Immunology, vol. 26, no. 1, pp. 29-32, 2009. 
[47] Y. J. Kang and K. H. Kim, "Effect of CpG-ODNs belonging to different classes on resistance of olive flounder (Paralichthys olivaceus) against viral hemorrhagic septicemia virus (VHSV) and Miamiensis avidus (Ciliata; Scuticociliatia) infections," Aquaculture, vol. 324-325, pp. 39-43, 2012.

[48] C. H. Lee, H. D. Jeong, J. K. Chung, H. H. Lee, and K. H. Kim, "CpG motif in synthetic ODN primes respiratory burst of olive flounder Paralichthys olivaceus phagocytes and enhances protection against Edwardsiella tarda," Diseases of Aquatic Organisms, vol. 56, no. 1, pp. 43-48, 2003.

[49] S. Ito, K. J. Ishii, M. Gursel, H. Shirotra, A. Ihata, and D. M. Klinman, "CpG oligodeoxynucleotides enhance neonatal resistance to Listeria infection," Journal of Immunology, vol. 174, no. 2, pp. 777-782, 2005.

[50] S. Raghavan, J. Nyström, M. Fredriksson, J. Holmgren, and A. M. Harandi, "Orally administered CpG oligodeoxynucleotide induces production of CXC and CC chemokines in the gastric mucosa and suppresses bacterial colonization in a mouse model of helicobacter pylori infection," Infection and Immunity, vol. 71, no. 12, pp. 7014-7022, 2003.

[51] M. Barrier, S. Lacroix-Lamandé, R. Mancassola et al., "Oral and intraperitoneal administration of phosphorothioate oligodeoxynucleotides leads to control of Cryptosporidium parvum infection in neonatal mice," Journal of Infectious Diseases, vol. 193, no. 10, pp. 1400-1407, 2006.

[52] D. Zipris, E. Lien, J. X. Xie, D. L. Greiner, J. P. Mordes, and A. A. Rossini, "TLR activation synergizes with Kilham rat virus infection to induce diabetes in BBDR rats," Journal of Immunology, vol. 174, no. 1, pp. 131-142, 2005.

[53] E. Uhlmann and J. Vollmer, "Recent advances in the development of immunostimulatory oligonucleotides," Current Opinion in Drug Discovery and Development, vol. 6, no. 2, pp. 204217, 2003.

[54] H. Tighe, K. Takabayashi, D. Schwartz et al., "Conjugation of protein to immunostimulatory DNA results in a rapid, longlasting and potent induction of cell-mediated and humoral immunity," European Journal of Immunology, vol. 30, no. 7, pp. 1939-1947, 2000.

[55] G. L. Morefield, A. Sokolovska, D. Jiang, H. Hogenesch, J. P. Robinson, and S. L. Hem, "Role of aluminum-containing adjuvants in antigen internalization by dendritic cells in vitro," Vaccine, vol. 23, no. 13, pp. 1588-1595, 2005.

[56] X. P. Ioannou, S. M. Gomis, B. Karvonen, R. Hecker, L. A. Babiuk, and S. Van Drunen Littel-Van Den Hurk, "CpGcontaining oligodeoxynucleotides, in combination with conventional adjuvants, enhance the magnitude and change the bias of the immune responses to a herpesvirus glycoprotein," Vaccine, vol. 21, no. 1-2, pp. 127-137, 2002.

[57] X. P. Ioannou, P. Griebel, R. Hecker, L. A. Babiuk, and S. Van Drunen Littel-Van den Hurk, "The immunogenicity and protective efficacy of bovine herpesvirus 1 glycoprotein $\mathrm{D}$ plus emulsigen are increased by formulation with $\mathrm{CpG}$ oligodeoxynucleotides," Journal of Virology, vol. 76, no. 18, pp. 9002-9010, 2002.

[58] R. D. Weeratna, M. J. McCluskie, Y. Xu, and H. L. Davis, “CpG DNA induces stronger immune responses with less toxicity than other adjuvants," Vaccine, vol. 18, no. 17, pp. 1755-1762, 2000.

[59] X. P. Ioannou, S. M. Gomis, R. Hecker, L. A. Babiuk, and S. Van Drunen Littel-van Den Hurk, "Safety and efficacy of CpGcontaining oligodeoxynucleotides as immunological adjuvants in rabbits," Vaccine, vol. 21, no. 27-30, pp. 4368-4372, 2003.
[60] H. Hemmi, O. Takeuchi, T. Kawai et al., "A Toll-like receptor recognizes bacterial DNA," Nature, vol. 408, no. 6813, pp. 740$745,2000$.

[61] H. Häcker, H. Mischak, T. Miethke et al., "CpG-DNA-specific activation of antigen-presenting cells requires stress kinase activity and is preceded by non-specific endocytosis and endosomal maturation," EMBO Journal, vol. 17, no. 21, pp. 6230$6240,1998$.

[62] A.-K. Yi and A. M. Krieg, "Cutting edge: rapid induction of mitogen-activated protein kinases by immune stimulatory $\mathrm{CpG}$ DNA," Journal of Immunology, vol. 161, no. 9, pp. 4493-4497, 1998.

[63] M. Gong, J. Zhou, C. Yang et al., "Insect cell-expressed hemagglutinin with $\mathrm{CpG}$ oligodeoxynucleotides plus alum as an adjuvant is a potential pandemic influenza vaccine candidate," Vaccine, vol. 30, no. 52, pp. 7498-7505, 2012.

[64] T. L. Roberts, M. J. Sweet, D. A. Hume, and K. J. Stacey, “Cutting edge: species-specific TLR9-mediated recognition of CpG and non-CpG phosphorothioate-modified oligonucleotides," Journal of Immunology, vol. 174, no. 2, pp. 605-608, 2005.

[65] J. Vollmer, R. D. Weeratna, M. Jurk et al., "Oligodeoxynucleotides lacking CpG dinucleotides mediate Toll-like receptor 9 dependent $\mathrm{T}$ helper type 2 biased immune stimulation," Immunology, vol. 113, no. 2, pp. 212-223, 2004.

[66] M. D. Fast, S. C. Johnson, and S. R. M. Jones, "Differential expression of the pro-inflammatory cytokines IL-1 $\beta-1, \mathrm{TNF} \alpha$ 1 and IL-8 in vaccinated pink (Oncorhynchus gorbuscha) and chum (Oncorhynchus keta) salmon juveniles," Fish and Shellfish Immunology, vol. 22, no. 4, pp. 403-407, 2007.

[67] C. M. A. Caipang, "Expression of genes involved in the early immune response at the distal segment of the gut in Atlantic cod, Gadus morhua L. after vaccination with a bacterial antigen," Aquaculture International, vol. 21, no. 3, pp. 591-603, 2013.

[68] I. E. Mulder, S. Wadsworth, and C. J. Secombes, "Cytokine expression in the intestine of rainbow trout (Oncorhynchus mykiss) during infection with Aeromonas salmonicida," Fish and Shellfish Immunology, vol. 23, no. 4, pp. 747-759, 2007.

[69] R. Gudding, A. Lillehaug, P. J. Midtlyng, and F. Brown, Fish Vaccinology: Developments in Biological Standardization, vol. 90, Karger, Basel, Switzerland, 1997.

[70] T.-N. Vinay, C.-S. Park, H.-Y. Kim, and S.-J. Jung, “Toxicity and dose determination of quillaja saponin, aluminum hydroxide and squalene in olive flounder (Paralichthys olivaceus)," Veterinary Immunology and Immunopathology, vol. 158, no. 1-2, pp. 73-85, 2014. 


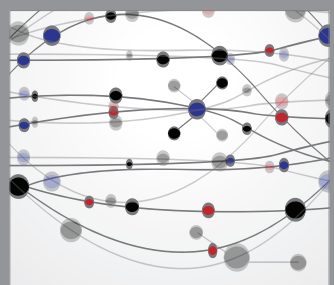

The Scientific World Journal
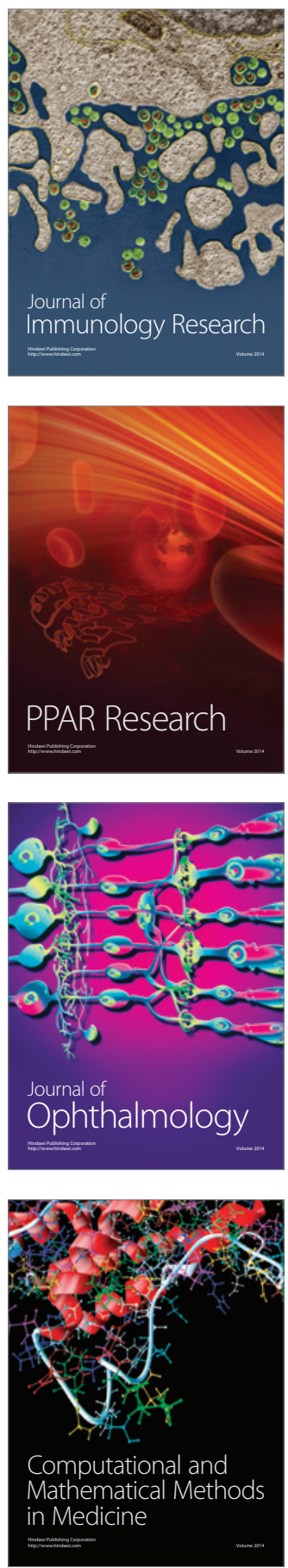

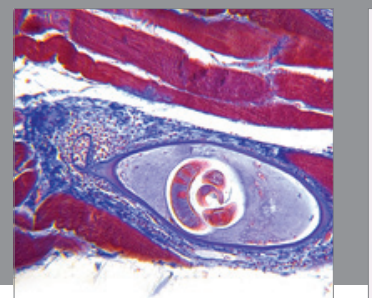

Gastroenterology

Research and Practice
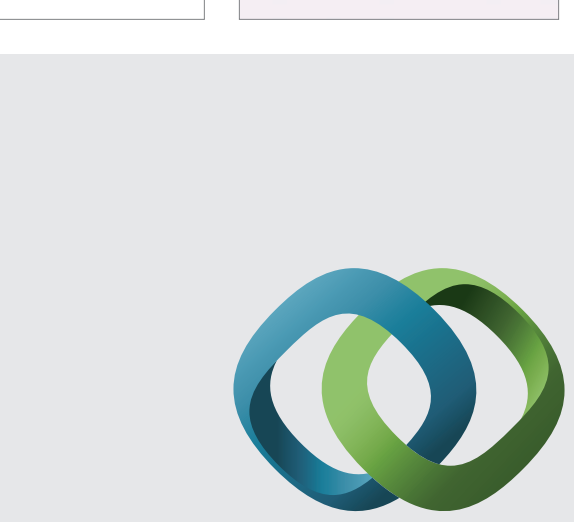

\section{Hindawi}

Submit your manuscripts at

http://www.hindawi.com
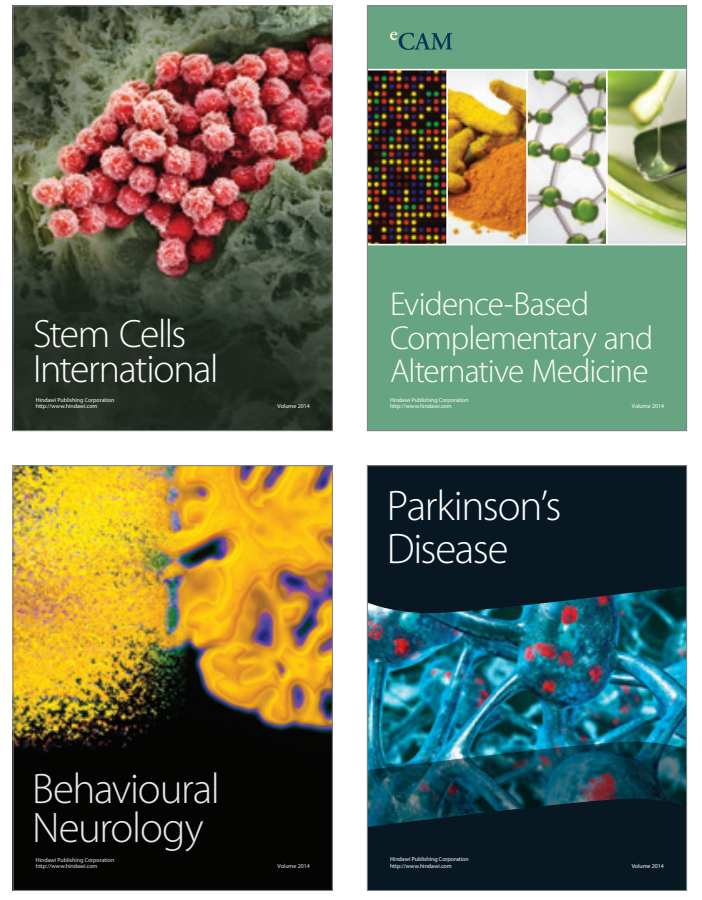
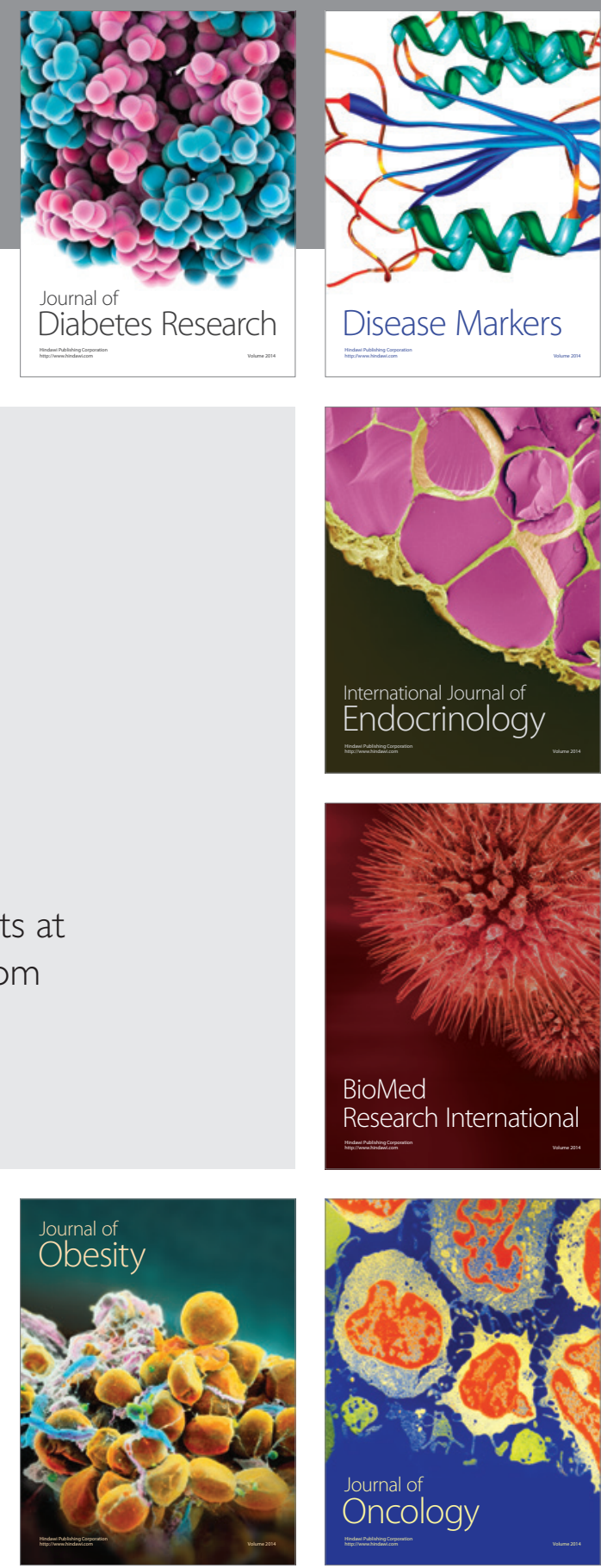

Disease Markers
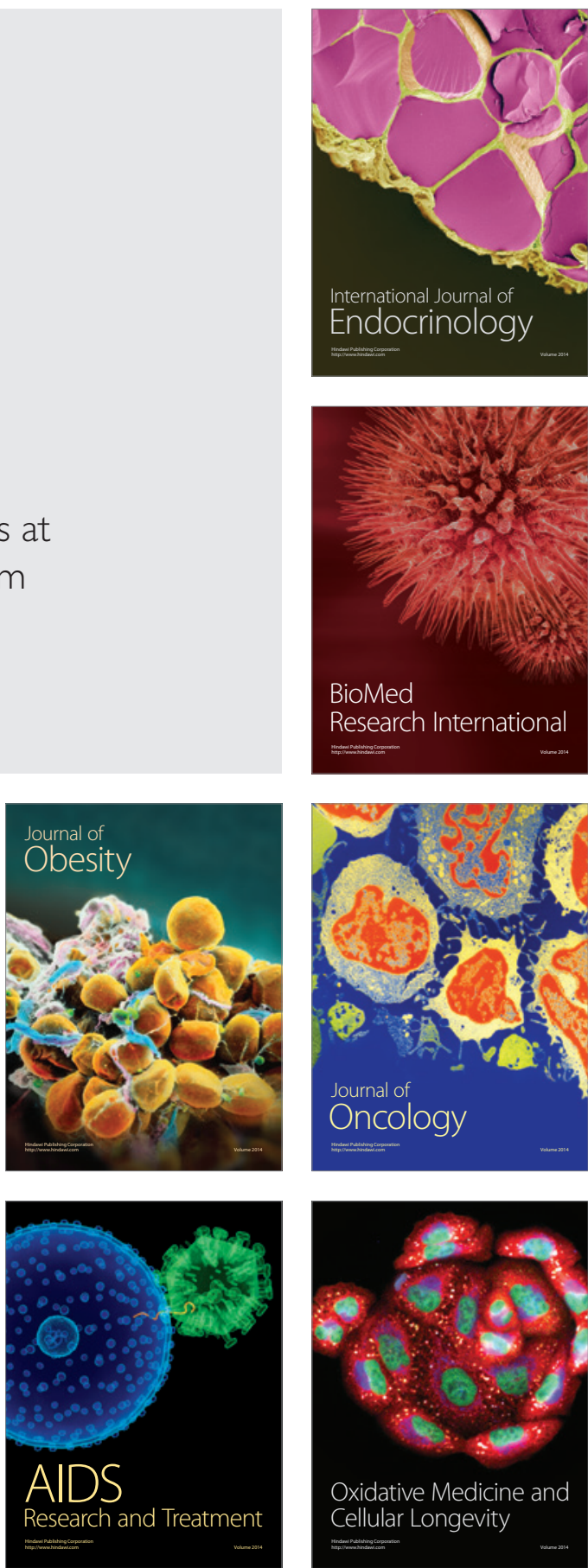